Gašparović, B., Penezić, A., Lampitt, R.S., Sudasinghe, N., Schaub, T. 2018. Phospholipids as a component of the oceanic phosphorus cycle. Mar. Chem. 250, 70-80.

Pre-print version

\title{
Phospholipids as a component of the oceanic phosphorus cycle
}

Blaženka Gašparović ${ }^{\mathrm{a}, *}$, Abra Penezića ${ }^{\mathrm{a}}$, Richard S. Lampitt ${ }^{\mathrm{b}}$, Nilusha Sudasinghe ${ }^{\mathrm{c}, \mathrm{d}}$, Tanner Schaub

${ }^{a}$ Division for Marine and Environmental Research, Ruđer Bošković Institute, POB 180, HR-10002

Zagreb, Croatia

${ }^{b}$ National Oceanography Centre, Southampton, United Kingdom SO14 3ZH

${ }^{c}$ College of Agricultural, Consumer and Environmental Sciences, New Mexico State University, United States

${ }^{\mathrm{d}}$ Bioscience Division, Los Alamos National Laboratory, Los Alamos, NM 87545, United States

${ }^{*}$ Correponding author. Tel.: +385 14561 148; fax: +38514680 242

E-mail address: gaspar@irb.hr (Blaženka Gašparović).

\section{Abstract}

We characterize the distribution of oceanic phosphorus-containing lipids (PL) in the Northeast Atlantic by Iatroscan thin layer chromatography and high resolution Fourier transform ion cyclotron resonance mass spectrometry (FT-ICR MS). Phospholipids are a small but significant fraction of oceanic particulate organic carbon (POC) (1.5\%). We describe the distribution of 1,862 PL compounds in total, of which only $\sim 27 \%$ have elemental compositions that match those found in the Nature Lipidomics Gateway database (e.g., phosphatidylglycerol (PG), phosphatidylcholine (PC), phosphatidylethanolamine (PE), phosphatidic acid (PA), phosphatidyl serine (PS), and phosphatidylinositol (PI)). The highest phospholipid concentration is found in the epipelagic, which reflects primary production in that depth horizon. Depthrelated PL removal was the strongest for PL signals that match database-reported (known) lipids and was lower for saturated non-database (novel) matched PL. The transformation of known PL is marked by depth-related increase in saturation with PA that is assumed to be generated as the earliest transformation product of PL. Novel unsaturated P-lipids likely originate from both PL transformation processes and insitu biological production at the surface layer. Novel PL are dominated by unsaturated compounds for which unsaturation increased between the epipelagic (average molecular double bond equivalents, $\mathrm{DBE}=5$ ) and the abyssopelagic (average DBE=6.7) zones. Additionally, those compounds increase in both average molecular weight and contribution to all lipid content with increasing depth, likely from crosslinking of unsaturated compounds. Our data indicate that novel PL are selectively preserved with depth and therefore are $\mathrm{P}$ and $\mathrm{C}$ carriers to the deep Atlantic. We demonstrate that a full appreciation of 
Gašparović, B., Penezić, A., Lampitt, R.S., Sudasinghe, N., Schaub, T. 2018. Phospholipids as a component of the oceanic phosphorus cycle. Mar. Chem. 250, 70-80.

Pre-print version

phosphorus cycling requires additional data on phospholipid composition and especially the ecological role and depth-related molecular change of these compounds.

Keywords: Phospholipids; phospholipid depth-related transformations; FT-ICR MS, TLC/FID; Northeast Atlantic Ocean

\section{Introduction}

Phosphorous $(\mathrm{P})$ is an essential nutrient for phytoplankton growth and in places limits oceanic primary production (Moore et al., 2013, Wu et al., 2000; Yoshimura et al., 2007). Phosphorus is a component of key molecules such as nucleic acids, phospholipids, ATP and complex carbohydrates. Unlike nitrogen, which can be supplied by nitrogen fixation in the euphotic zone, the supply of other macro-nutrients is dominated by deep mixing and upwelling (Dugdale and Goering, 1967). Phosphorus supply to the ocean depends on continental input. River runoff represents the main phosphorus source in the ocean (Baturin, 2003). However, there is no atmospheric reservoir of phosphorus. Moreover, the phosphorus budget of the ocean is unbalanced since the accumulation of phosphorus in marine sediments and altered oceanic crust exceeds the continental input of particulate and dissolved phosphorus (Wallmann, 2010).

Various chemical forms of $\mathrm{P}$ participate in numerous abiotic and biotic processes collectively referred to as the $\mathrm{P}$ cycle, which is strongly connected to the carbon cycle and therefore to the capability of oceans for climate change mitigation due to their capacity to sequester carbon from the atmosphere. A crucial process in this is the generation of carbon-rich material in the upper ocean. The particles export a fraction of the primary production out of the euphotic zone (i.e. the "biological carbon pump"). Export flux of POC is less than 5-10\% of total primary production in the ocean (Buesseler, 1998). Any organic carbon that escapes mineralization in this environment is liable to be sequestered for millennia, ultimately representing the sequestration of atmospheric $\mathrm{CO}_{2}$ (Lampitt et al., 2008). Microorganisms are primarily responsible for carbon (Azam, 1998) and P (Karl, 2014) assimilation and remineralization in the ocean.

Lipids are a major biochemical class in seawater along with carbohydrates and proteins. They are carbon rich, with a high energetic value, and thus represent important metabolic fuels. Phosphorus containing lipids (i.e. phospholipids) are a major component of cell membranes that provide structure and protection to cells. Membrane lipids generally contribute to 15 to $25 \%$ of the carbon in planktonic cells 
Gašparović, B., Penezić, A., Lampitt, R.S., Sudasinghe, N., Schaub, T. 2018. Phospholipids as a component of the oceanic phosphorus cycle. Mar. Chem. 250, 70-80.

Pre-print version

(Wakeham et al., 1997). The synthesis of phospholipids consumes $18-28 \%$ of the $\mathrm{PO}_{4}{ }^{3-}$ taken up by the total planktonic community in the North Pacific subtropical gyre (Van Mooy et al., 2006). The proportion of PL in phytoplankton varies widely from a few percent to as much as half of the total lipid content. Nutrient conditions affect the composition of cellular lipid composition in phytoplankton; diatoms grown under nutrient replete conditions exhibit high proportions of PL, while in P-depleted conditions PL content is dramatically reduced (Geider and La Roche, 2002; Martin et al., 2011a). Phospholipids comprise a significant proportion of cellular phosphorus (e.g., 36\% and 15-20\% of cellular P of the freshwater phytoplankton Ankistrodesmus folcatus (Geider and La Roche, 2002) and marine bacteria (Dobbs and Findlay, 1993) respectively. On average, PL account for $4 \pm 1 \%$ and $7.1 \pm 2.5 \%$ of the total particulate phosphorus in the eastern subtropical South Pacific and in the Medditerranean, respectively (Van Mooy and Fredrichs, 2010, Poppendorf et al., 2011). Dominant phospholipid molecules vary by plankton species. Heterotrophic bacteria are the dominant sources of phosphatidylglycerol (PG) and phosphatidylethanolamine (PE), while PC phosphatidylcholines (PC) are derived primarily from eukaryotic phytoplankton (Van Mooy and Fredricks, 2010).

Phospholipid concentration varies between marine environments. Particulate PL concentrations in the northern Adriatic, Mediterranean, throughout a year vary in the range of 3.0 to $27.7 \mu \mathrm{g} / \mathrm{l}$, with a contribution to total lipids between 17.8 and 50.3\% (Frka et al., 2011; Marić et al., 2013) as measured by thin layer chromatography. PL in the oligotrophic to mesotrophic region of the east Atlantic, measured by thin layer chromatography, ranged from 1.3 to $7.8 \mu \mathrm{g} / \mathrm{l}$, contributing between 11.4 and $55.0 \%$ of total lipid content (Gašparović et al., 2014). In the upper $250 \mathrm{~m}$ of the oceanic water column, concentrations of measured PL (PG+PE+PC) in the eastern subtropical South Pacific ranged between 130-1350 pmol/1 (Van Mooy and Fredrichs, 2010). The depth distribution of the three phospholipids (PG, PE, and PC) across the Mediterranean Sea was quite similar, each phospholipid class was approximately 200-600 pmol/1 in the surface, increasing to $200-800 \mathrm{pmol} / \mathrm{l}$ at 50-75 m, then decreasing to 100-200 pmol/1 at $250 \mathrm{~m}$ (Popendorf et al., 2011). There is a wide variability in P-related physiology among marine plankton, including the ability to acquire and utilize different organic P sources (Ivančić et al., 2012), and the substitution of PL with non-phosphorus lipids in P-limited conditions (Van Mooy et al., 2009; Sebastián et al., 2016).

The transformation processes of phosphorus-containing molecules within the water column remain poorly understood (Benitez-Nelson, 2000), particularly related to their degradation (Rontani et al., 2009; 
Gašparović, B., Penezić, A., Lampitt, R.S., Sudasinghe, N., Schaub, T. 2018. Phospholipids as a component of the oceanic phosphorus cycle. Mar. Chem. 250, 70-80.

Pre-print version

Rontani et al., 2012). To our knowledge, there are no published reports on oceanic phospholipid degradation processes, but they are clearly an essential resource for some deep ocean organisms that are unable to synthesise them (Mayor et al., 2013; Pond et al., 2014).

Given the importance of $\mathrm{P}$ as a major limiting nutrient, we are interested in the surface Atlantic production of phospholipids and their potential as a phosphorus and carbon carrier to the deep ocean. There is a pressing need to understand the processes involved in the early transformation of PL that are responsible for chemical change in terms of both concentration and molecular characteristics. To address this issue we performed complete phospho-lipidomic analysis by direct-infusion FT-ICR MS. Molecular formulae are derived directly from FT-ICR MS measurement and subsequently matched to a lipid database. While this approach neglects isomeric identification, it is the only measure available that provides global description for multiple thousands of organic molecules in these environments. With these data, we characterize the nature of particulate PL, their removal and transformations through the water column. In addition we used thin-layer chromatography with flame ionization detection to quantitatively detect total lipid and bulk phospholipid to complement the FT-ICR MS analysis and illuminate the modern P cycle.

\section{Methods}

\subsection{Location}

The study site, of the Porcupine Abyssal Plain Sustained Observatory (PAP-SO) in the Northeast Atlantic (49N, 16.5W) (Fig. 1) has been the main focus of many studies since 1992. This region is isolated from the complexities of the continental slope and the Mid-Atlantic Ridge. A persistent feature of the North Atlantic is undersaturation of $\mathrm{CO}_{2}$ in surface waters throughout the year, which gives rise to a perennial $\mathrm{CO}_{2}$ sink and makes this a region of great importance in the global carbon cycle (Hartman et al., 2012). In terms of biogeographical provinces that have dynamical boundaries, it is well within the North Atlantic Drift (NADR) province (Longhurst, 2007), which is generally characterized with spring bloom that is developing from the late April, starting at the southern part of NADR and progressing northward until June. The influences of the continental shelves and slope are thought to be slight at PAP with 
Gašparović, B., Penezić, A., Lampitt, R.S., Sudasinghe, N., Schaub, T. 2018. Phospholipids as a component of the oceanic phosphorus cycle. Mar. Chem. 250, 70-80.

Pre-print version

negligible advection of particulate material (Weaver et al., 2000). Eddy activity is much lower than in many other oceanic regions (Chelton et al., 2007), and such as they are, they tend not to traverse quickly. Currents are generally weak (Lampitt et al., 2001) and lateral advection speeds are low but significant (Williams et al., 2006; Hartman et al., 2010).

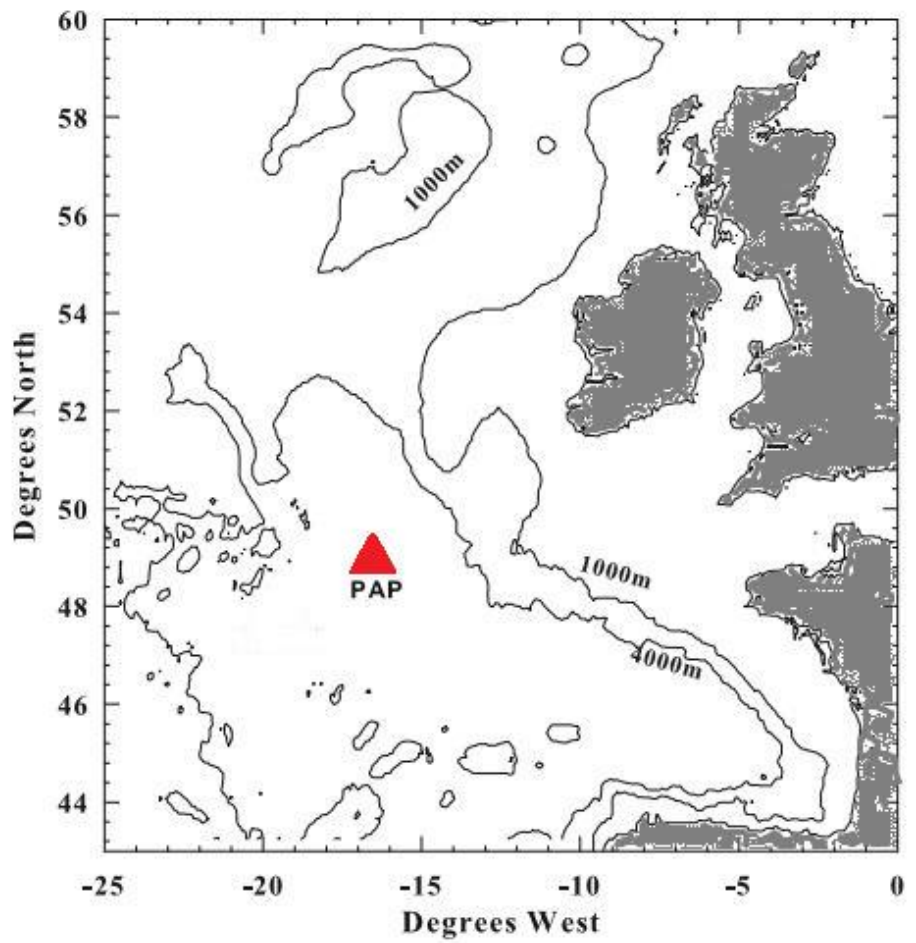

Fig. 1. PAP sampling site.

\subsection{Sample processing}

Sampling was conducted at the PAP station from the RRS James Cook on June 14, 2013. Ocean samples were collected at 21 depths from the surface $(2 \mathrm{~m})$ to $4800 \mathrm{~m}$ (50 $\mathrm{m}$ above bottom) (epipelagic $(0-100 \mathrm{~m})$, mesopelagic $(100-1000 \mathrm{~m})$, bathypelagic $(1000-4000 \mathrm{~m})$ and abyssopelagic $(4000-4900 \mathrm{~m}))$ from a pre-dawn ( 0400 local time) Seabird 911+CTD-Niskin rosette. Six of the surface sampled depths (2-100 m depth) corresponded to $97,55,20,7,5$ and $1 \%$ of surface irradiance intensity.

Particulate lipids were collected on board on $0.7 \mu \mathrm{m}$ Whatman $\mathrm{GF} / \mathrm{F}$ filters combusted at $450^{\circ} \mathrm{C} / 5 \mathrm{~h}$ by filtering 5-10 1 of oceanic water at $12 \mathrm{kPa}$ vacuum pressures immediately after sampling and stored at $-80^{\circ} \mathrm{C}$ until analysis. 
Gašparović, B., Penezić, A., Lampitt, R.S., Sudasinghe, N., Schaub, T. 2018. Phospholipids as a component of the oceanic phosphorus cycle. Mar. Chem. 250, 70-80.

Pre-print version

\subsection{Basic environmental parameters}

Temperature, salinity, and oxygen measurements were made using Seabird SBE 37-IM recorders (Sea-Bird Electronics Inc., Bellevue, Washington, USA). Samples for nutrient (total inorganic nitrogen $\left(\mathrm{TIN}=\right.$ nitrate $\left(\mathrm{NO}_{3}^{-}\right)+$nitrite $\left(\mathrm{NO}_{2}^{-}\right)+$ammonium $\left.\left(\mathrm{NH}_{4}^{+}\right)\right)$, orthophosphate $\left(\mathrm{PO}_{4}{ }^{3-}\right)$ and orthosilicate $\left.\left(\mathrm{SiO}_{4}{ }^{4-}\right)\right)$ analysis were drawn into $25 \mathrm{ml}$ plastic coulter counter vials from Niskin bottles. The vials were stored in the dark at $4^{\circ} \mathrm{C}$ until analysis, which commenced within 24 hours of sampling. Nutrients were determined in triplicate in unfiltered water samples with a Skalar Sanplus segmented flow autoanalyzer and standard colorimetric techniques described by Kirkwood (1996).

Fluorometric measurements of total Chlorophyll $a(\mathrm{Chl} a)$ were made on board by filtration of 250 $\mathrm{ml}$ of seawater through Whatman $\mathrm{GF} / \mathrm{F}$ (nominal pore size $0.7 \mu \mathrm{m}$ ) glass fibre filters, extraction of the filters in $10 \mathrm{ml}$ of $90 \%$ acetone (HPLC grade) for $18-20 \mathrm{~h}$ (dark, $41^{\circ} \mathrm{C}$ ) and determination of chlorophyll fluorescence with a TD-700 (Turner Designs) fluorimeter (after Welschmeyer, 1994). Size-fractionated Chl $a$ measurements were made by sequential filtering of 1.21 of seawater through 10 and $2 \mu \mathrm{m}$ polycarbonate filters (Fileder Filter Systems, UK), and extraction with GF/F filters to provide a comparison between micro- and nanophytoplankton derived Chl $a$. Filtering was performed on board and filters were stored at $-80^{\circ} \mathrm{C}$ until analysis.

\subsection{Lipid extraction and measurements}

Lipids were extracted on land by a modified one-phase solvent mixture of dichloromethane methanol - water procedure (1:2:0.8, v:v:v) (Blight and Dyer,1959). One $\mu \mathrm{g}$ of the internal standard reserpine was added to each sample before extraction for FT-ICR MS. Mass spectral peak magnitude for each compound was normalized (in both modes) to the internal standard (i.e. reserpine) peak magnitude, so that the mass spectral signals for each compound could be normalized to a fixed volume of seawater. Ten $\mu \mathrm{g}$ of hexadecanone was added to each sample before extraction for Iatroscan analysis. This internal standard was then extracted with the lipids in the sample, and the amount measured in the final concentrate provided an estimate of lipid recovery. The lipid extraction efficiency was between 81 and $105 \%$. Extracts were concentrated by rotary evaporation and brought to dryness under a nitrogen atmosphere. 
Gašparović, B., Penezić, A., Lampitt, R.S., Sudasinghe, N., Schaub, T. 2018. Phospholipids as a component of the oceanic phosphorus cycle. Mar. Chem. 250, 70-80.

Pre-print version

160

161

162

163

164

165

166

167

168

169

170

171

172

173

174

175

176

177

178

179

180

181

182

183

184

185

186

187

188

189

The particulate-derived lipid material collected was analyzed by direct-infusion electrospray ionization Fourier transform ion cyclotron resonance mass spectrometry (ESI FT-ICR MS) in both negative and positive ionization mode to provide elemental composition determination for lipids that can serve as diagnostic markers for their origin, transformation and preservation potential through the ocean water column. ESI FT-ICR mass spectrometry was performed with a hybrid linear ion trap 7 T FT-ICR mass spectrometer (LTQ FT, Thermo Fisher, San Jose, CA) equipped with an Advion Triversa Nanomate (Advion Biosystems, Inc.) as previously described (Holguin and Schaub, 2013). FT-ICR mass spectra were acquired at a mass resolving power of $\mathrm{m} / \Delta \mathrm{m} 50 \%=400,000$ at $\mathrm{m} / \mathrm{z} 400$ (i.e. a time-domain acquisition period of $\sim 3 \mathrm{~s}$ ). A total of 500 time-domain transients were co-added for each sample in both positive and negative ionization modes prior to fast Fourier transformation and frequency to mass-tocharge ratio conversion. FT-ICR mass spectra were internally calibrated to achieve sub part-per-million mass measurement accuracy which facilitates direct assignment of elemental composition from measured $\mathrm{m} / \mathrm{z}$ ratio and peak lists were generated from each mass spectrum at $\mathrm{S} / \mathrm{N}>10$. Internal calibration of the mass spectra was performed using homologous alkylation series of known compounds where elemental compositions differ by integer multiples of $\mathrm{CH}_{2}$. High-resolution FT-ICR mass spectra confirm that all observed ions are single charged as evidenced by the 1 Da spacing between ${ }^{12} \mathrm{C}_{\mathrm{c}}$ and ${ }^{13} \mathrm{C}_{1}{ }^{12} \mathrm{C}_{\mathrm{c}-1}$ peaks for the species with the same molecular formula. IUPAC measured masses $\left(\mathrm{CH}_{2}=14.01565 \mathrm{Da}\right)$ were converted to the Kendrick mass scale $\left(\mathrm{CH}_{2}=14.0000\right.$ Kendrick mass units $)$ as previously described (Kendrick, 1963) and sorted by the Kendrick mass defect to facilitate identification of homologous series with the same heteroatom composition and the same double-bond equivalents (DBE) but differing in the degree of alkylation. DBE was calculated as follows: $\mathrm{DBE}=\mathrm{C}+1-\mathrm{H} / 2+\mathrm{N} / 2$ (halogens omitted because they were not observed in our analysis). Mass spectral peak magnitude for each compound was normalized (in both modes) to the internal standard (i.e. reserpine) peak magnitude, so that the mass spectral signals for each compound could be normalized to a fixed volume of seawater.

High mass measurement accuracy and mass resolving power combined with Kendrick mass sorting and isotopic fine structure analysis enables robust determination of elemental compositions for individual lipid compounds present in these extracts. Derived elemental compositions are matched to an in-house assembled lipid library derived from Lipid Maps (http://www.lipidmaps.org/). For the purposes of this paper, elemental compositions for which multiple database isomeric matches are possible, further identification was not attempted. In cases where we discuss specific lipid molecular classes, those 
Gašparović, B., Penezić, A., Lampitt, R.S., Sudasinghe, N., Schaub, T. 2018. Phospholipids as a component of the oceanic phosphorus cycle. Mar. Chem. 250, 70-80.

Pre-print version

190

compounds represent elemental compositions for which only one database match is made. Relative abundance for certain PL class is calculated by normalization of that PL class peak magnitude at each depth to the lowest measured that PL peak magnitude across the depth profile. Compounds for which elemental composition matches one or more lipid in the database are termed "database-matched" or "known" and non-database matched compounds are termed "novel" for this discussion.

Additionally, total lipid and lipid class quantitation was performed by IATROSCAN thin layer chromatography/flame ionization detection (TLC/FID) (Iatroscan MK-VI, Iatron, Japan). Lipids were separated on silica-coated quartz thin-layer chromatography (TLC) rods (Chromarods SIII) (SESAnalysesysteme, Germany) and quantified by an external calibration with a standard lipid mixture. The lipid class quantification was achieved using calibration curves obtained for a standard by plotting peak area against lipid amount spotted. Hydrogen flow rate was $160 \mathrm{ml} / \mathrm{min}$ and air flow rate was $2000 \mathrm{ml} / \mathrm{min}$. Each lipid extract was analyzed in duplicate: for the analysis, $2 \mu \mathrm{l}$ aliquots of $20 \mu \mathrm{l}$ of the solution in dichloromethane were spotted by semiautomatic sample spotter. The standard deviation determined from duplicate runs accounted for $0-9 \%$ of the relative abundance of lipid classes.

The separation scheme of 18 lipid classes involve subsequent elution steps in the solvent systems of increasing polarity. For the separation of PG, PE and PC last two solvent system including solvent mixture acetone-chloroform-methanol-formic acid (33:33:33:0.6, v:v:v:v) during 40 min for PG separation. Finally, solvent mixture chloroform-methanol-ammonium hydroxide (50:50:5, v:v:v) during 30 min allowed separation of PE and PC, and non-lipid material which remained at the origin. Total lipid concentration was obtained by summing all lipid classes quantified by TLC-FID. Details of the procedure are described in Gašparović et al. (2015; 2017).

\subsection{Particulate organic carbon analysis}

Seawater samples (1 l collected from the CTD rosette were prepared by filtering onto combusted $25 \mathrm{~mm} \mathrm{GF} / \mathrm{F}$ filters and stored on board at $-20{ }^{\circ} \mathrm{C}$ for subsequent particulate organic carbon (POC) analysis. Inorganic carbonates were removed from the filters by acidification with fuming concentrated hydrochloric acid. The filters were dried in the oven at $50{ }^{\circ} \mathrm{C}$ for $24 \mathrm{~h}$, packaged in pre-combusted tin capsules and analysed with an Automated Nitrogen Carbon Analysis for Gas, Solids and Liquids (ANCAGSL) preparation system coupled to a PDZ Europa 20-20 Stable Isotope Analyzer (PDZ Europa Scientific 
Gašparović, B., Penezić, A., Lampitt, R.S., Sudasinghe, N., Schaub, T. 2018. Phospholipids as a component of the oceanic phosphorus cycle. Mar. Chem. 250, 70-80.

Pre-print version

219

Instruments, Northwich, UK). The mass spectrometer can be tuned using source settings for sensitivity and/or linearity of a standard range. A typical standard range used for linearity is $25-1028 \mu \mathrm{g}$ carbon, the limit of detection being 3 times the standard deviation of the blank of an analysis. The blank consisting of a tin capsule is analyzed in triplicate.

\subsection{Pigment analysis}

Pigment data are derived from the same set of FT-ICR MS data as for phospholipids (c.f. paragraph 2.4).

\section{Results}

Environmental conditions during the cruise to the PAP-SO from May $31^{\text {st }}$ to June $18^{\text {th }}, 2013$ are presented in Fig. 2. Although sampling was performed on the penultimate day of the cruise period, we present environmental conditions for the whole cruise period to get insight into conditions that preceded PL production and their export to the deep ocean. We assume that PL found below the euphotic zone were produced during the previous days. During the course of the cruise the temperature decreased from 14.3 to $11.3^{\circ} \mathrm{C}$ from the surface to $200 \mathrm{~m}$, while salinity varied slightly between 35.35 and 35.70 . Orthophosphate concentration increased with depth from 0.01 to $0.88 \mu \mathrm{mol} \mathrm{L}^{-1}$ (average $0.44 \mu \mathrm{mol} \mathrm{L}{ }^{-1}$ ) and the TIN concentrations were in the range of 0.26 to $12.26 \mu \mathrm{mol} \mathrm{L}^{-1}$ (average $5.09 \mu \mathrm{mol} \mathrm{L}^{-1}$ ). $\mathrm{SiO}_{4}{ }^{4-}$ concentration increased from 0.06 to $6.58 \mu \mathrm{mol} \mathrm{L}^{-1}$ from the surface to $250 \mathrm{~m}$ depth (average $1.15 \mu \mathrm{mol}$ $\left.\mathrm{L}^{-1}\right)$ and the surface productive layer $(0-50 \mathrm{~m})$ showed a low concentration of $\mathrm{SiO}_{4}{ }^{4-}$ with an average concentration of $0.65 \mu \mathrm{mol} \mathrm{L}^{-1}$. There is a continuous concentration increase of all nutrients from $250 \mathrm{~m}$ to $4800 \mathrm{~m}$ depth, reaching concentrations of $22.99 \mu \mathrm{mol} \mathrm{L}^{-1} \mathrm{TIN}, 1.89 \mu \mathrm{mol} \mathrm{L}^{-1} \mathrm{PO}_{4}{ }^{3-}$ and $44.35 \mu \mathrm{mol} \mathrm{L}^{-}$ ${ }^{1} \mathrm{SiO}_{4}{ }^{4-}$ (Gašparović et al., 2017). 
Gašparović, B., Penezić, A., Lampitt, R.S., Sudasinghe, N., Schaub, T. 2018. Phospholipids as a component of the oceanic phosphorus cycle. Mar. Chem. 250, 70-80.

Pre-print version
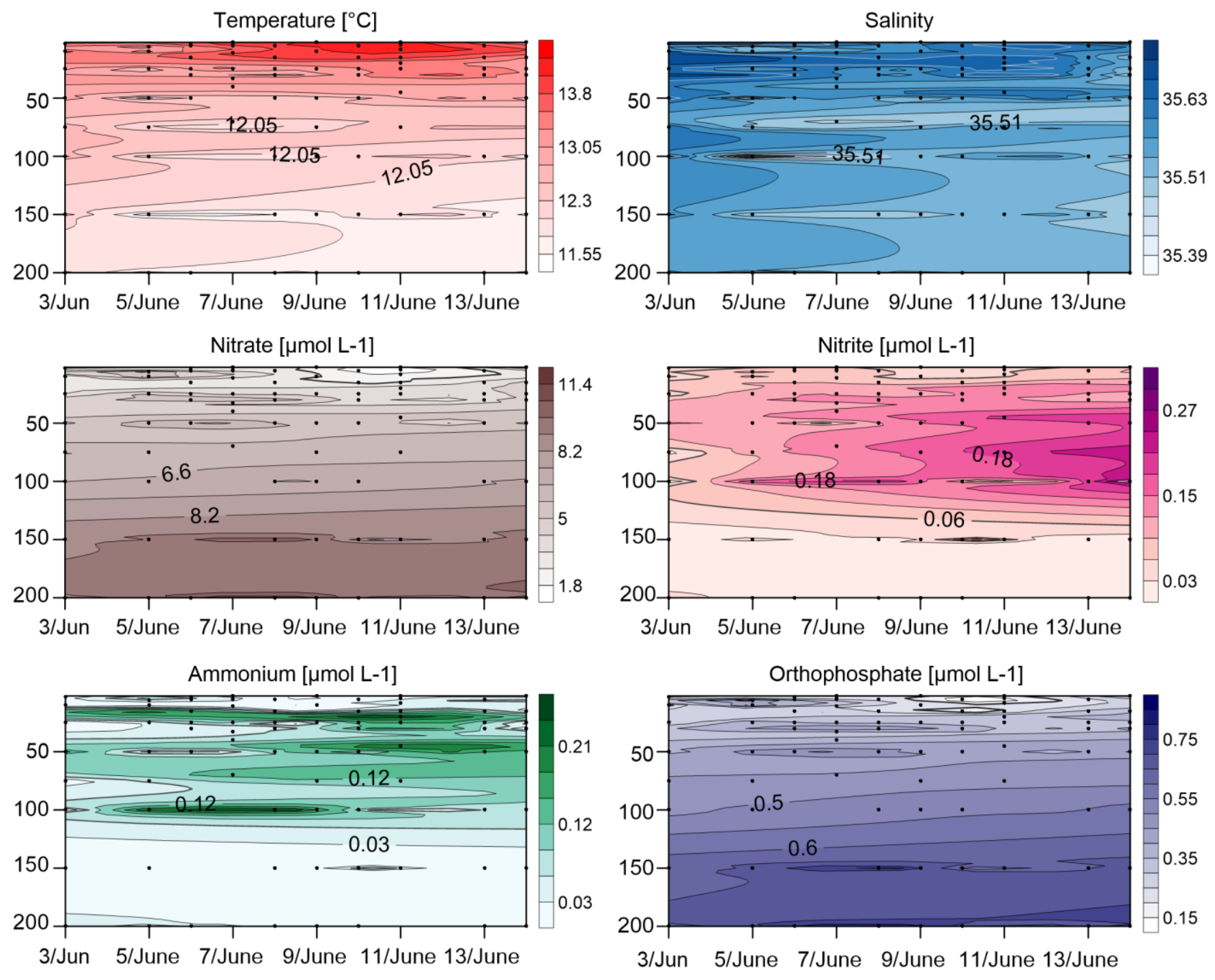

Orthosilicate $[\mu \mathrm{mol} \mathrm{L-1}]$

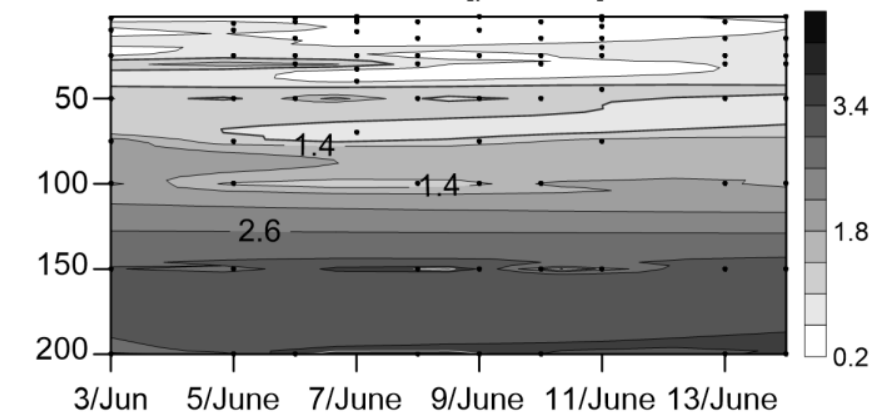

Fig. 2. Depth distributions at PAP station of a) temperature, b) salinity, c) nitrates, d) nitrites, e) 246 ammonium, f) orthophosphates, and g) orthosilicates during the subpolar Northeast Atlantic cruise (the 247 Porcupine Abyssal Plain) during the whole cruise period. Sampling for the lipid analysis was performed 248 on June $14^{\text {th }} 2013$. 
Gašparović, B., Penezić, A., Lampitt, R.S., Sudasinghe, N., Schaub, T. 2018. Phospholipids as a component of the oceanic phosphorus cycle. Mar. Chem. 250, 70-80.

Pre-print version

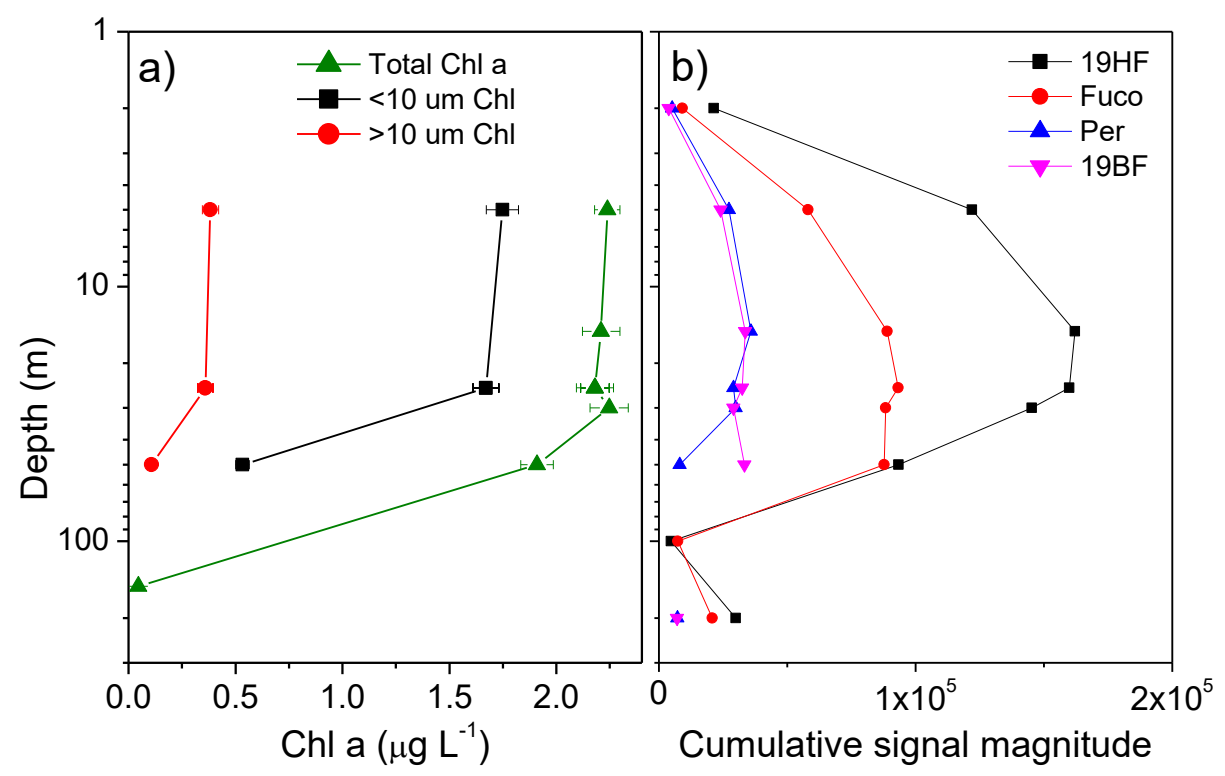

Fig. 3. Depth related (a) total Chl $a$ and size-fractionated Chl $a$ distributions and (b) changes of the pigment FT-ICR MS cumulative signal magnitude of 19'-Hexanoyloxyfucoxanthin (19HF) (squares), Fucoxanthin (Fuco), (circles), Peridinin (Peri) (triangles) and 19'-Butanoyloxyfucoxanthin (19BF) (down triangles).

Depth related distributions of chlorophyll $a(\mathrm{Chl} a)$ and other pigments observed in the whole water column are shown in Fig. 3. Chl $a$ shows the highest concentration at the first $50 \mathrm{~m}$ depth. Sizefractionated $\mathrm{Chl} a$ measurements revealed that the highest contribution to the total $\mathrm{Chl} a$ derived from nanophytoplankton (<10 $\mu \mathrm{m}$ fraction) (82\%), whereas microphytoplankton ( $>10 \mu \mathrm{m}$ fraction) only contributed to about $18 \%$ of the total $\mathrm{Chl} a$. A similar situation was observed at other times during the cruise (data not shown).

The FT-ICR MS data provide identification of the main phytoplankton pigments. 19'Hexanoyloxyfucoxanthin (19HF), Fucoxanthin (Fuco), Peridinin (Peri) and 19'-Butanoyloxyfucoxanthin (19BF), shown in Fig. 3b, serve as markers for prymnesiophytes, diatoms, dinophyceae and chrysophytes, respectively. The most abundant signals are observed for pigments that serve as markers for prymnesiophytes (nanophytoplankton) and for diatoms (microphytoplankton). technique provides information on total lipid content close to true gravimetric values (Parrish, 1987), which are important for lipid mass balance calculation. Total lipids ranged from 3.0 to $24.3 \mu \mathrm{g} \mathrm{L}^{-1}$. The average decrease in total lipid content between the epipelagic and the abyssopelagic was $64 \%$. The highest 
Gašparović, B., Penezić, A., Lampitt, R.S., Sudasinghe, N., Schaub, T. 2018. Phospholipids as a component of the oceanic phosphorus cycle. Mar. Chem. 250, 70-80.

Pre-print version

268

decrease was observed between the epipelagic and the mesopelagic. The Iatroscan TLC-FID technique detected 3 classes of phospholipids: PG, PC, and PE, which are summed and reported as PL. There is no protocol to detect phosphatidic acid (PA), phosphatidyl serine (PS) and phosphatidylinositol (PI) by Iatroscan TLC-FID. However, PS and PA co-elute with PG, while PI co-elute with PC. PL varied between $5.7 \mu \mathrm{g} \mathrm{L}^{-1}$ at $30 \mathrm{~m}$ depth and $0.6 \mu \mathrm{g} \mathrm{L}^{-1}$ at $3500 \mathrm{~m}$ depth. The decrease in PL between the epipelagic and the abyssopelagic is $77 \%$. The PL contribution to total lipids was highest in the epipelagic and the lowest in the mesopelagic. The highest contribution was measured for the $30 \mathrm{~m}$ depth $(25.7 \%)$ and the lowest for the $400 \mathrm{~m}$ depth $(12.6 \%)$.

The water column POC profile shows surface POC enrichment (up to $202.3 \mu \mathrm{g} \mathrm{L}^{-1}$ ) and a decrease in concentration with depth (down to $24.3 \mu \mathrm{g} \mathrm{L}^{-1}$ ) (Fig. 4b). We do not have POC data for the whole water column due to the irreparable damage to the samples during preparation. The contribution of PL to POC range from 0.63 to $2.58 \%$ with an average of $1.54 \%$ (Fig. $4 \mathrm{c}$ ).

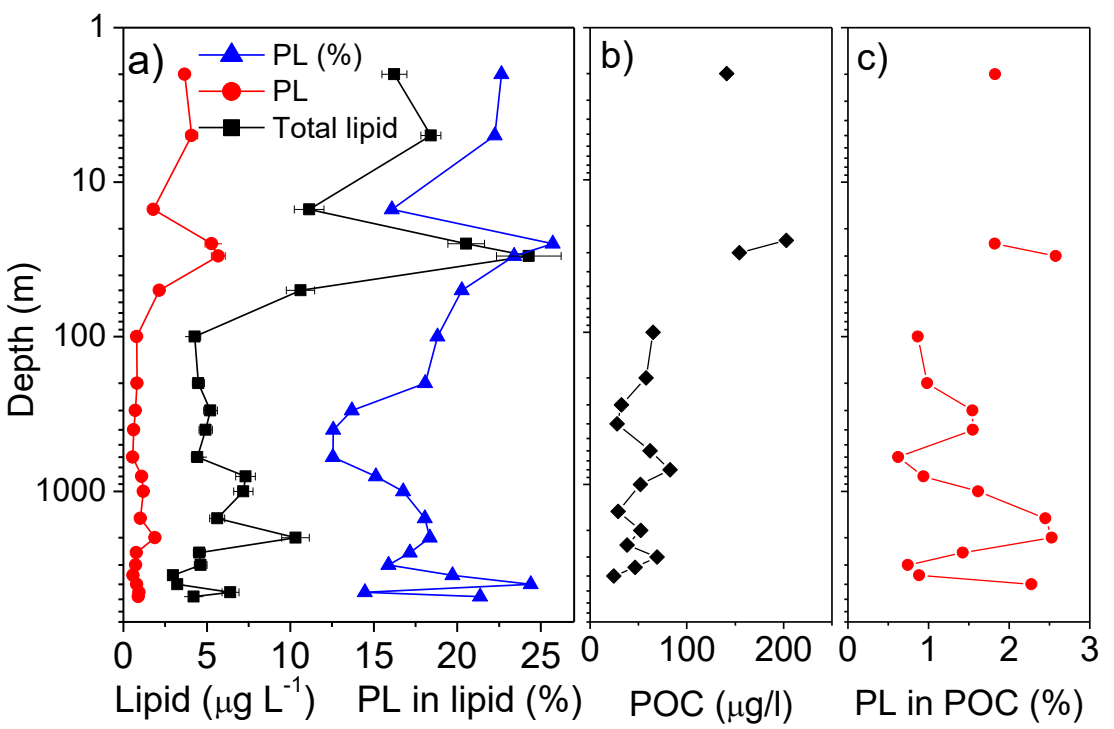

Fig. 4. Depth distribution of Iatroscan determined (a) total particulate lipids (squares), phospholipids (PL) (circles), and the \% contribution of PL to total lipids (triangles) and (b) POC and (c) the \% contribution of PL to POC.

The principal drawback of Iatroscan TLC/FID is its inability to resolve individual molecular compounds in complex samples, thus providing only limited information on the sample composition. Therefore, we performed direct infusion high resolution FT-ICR mass spectrometry to provide a detailed molecular-level compositional description of the samples. High mass accuracy and mass resolving power 
Gašparović, B., Penezić, A., Lampitt, R.S., Sudasinghe, N., Schaub, T. 2018. Phospholipids as a component of the oceanic phosphorus cycle. Mar. Chem. 250, 70-80.

Pre-print version

in combination with Kendrick mass sorting enable unambiguous determination of elemental composition for $\sim 5,000$ individual lipid compounds present in this sample set for negative ions and >8,500 compounds between both ion polarities.
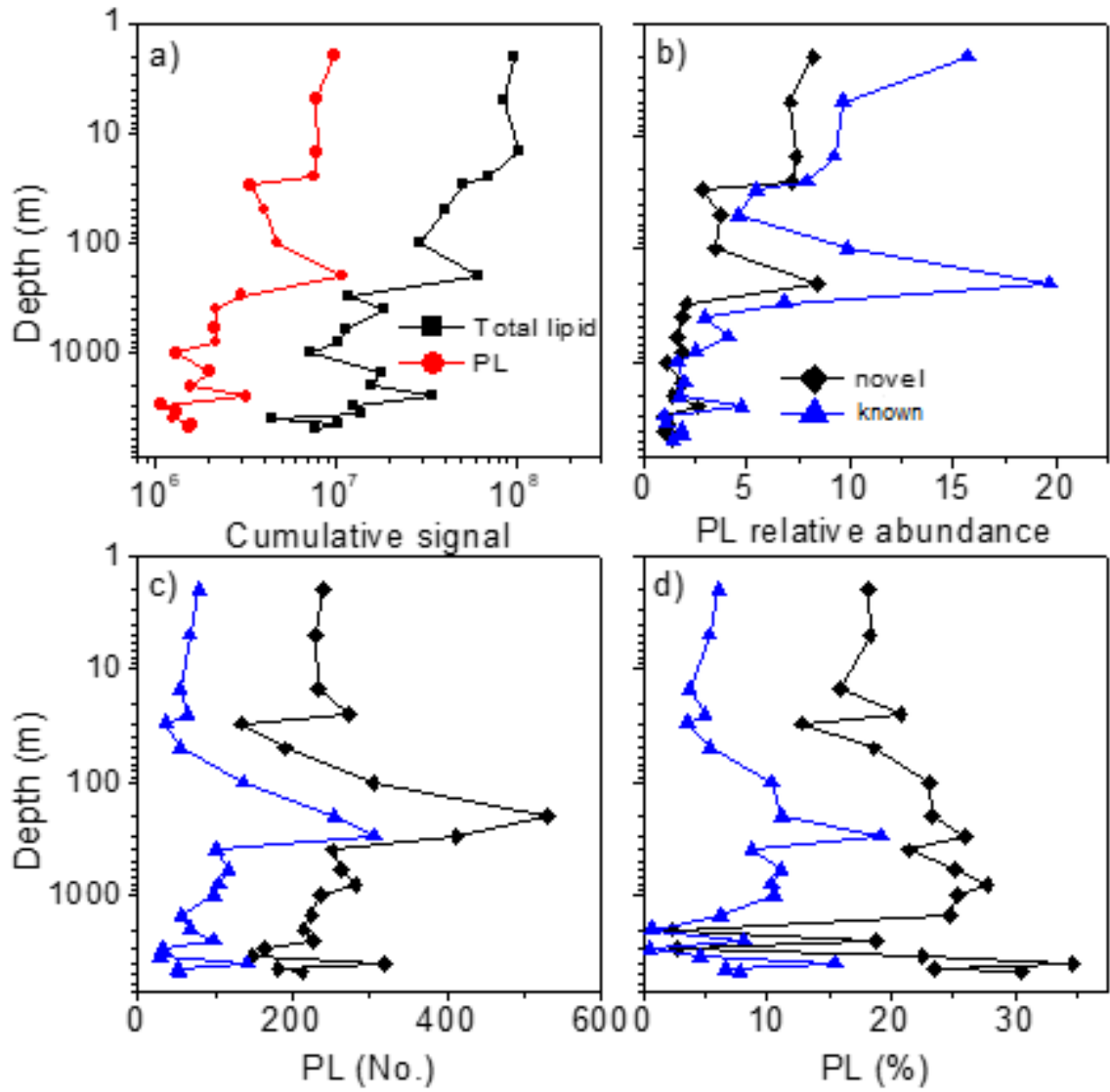

PL relative abundance

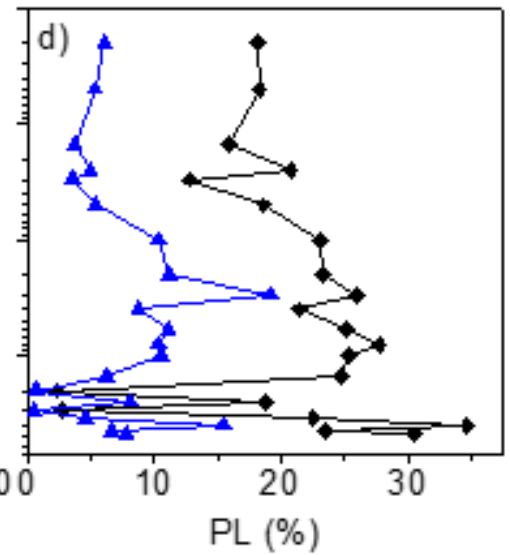

Fig. 5. Depth distribution of FT-ICR MS-determined (a) Total particulate lipid (squares), phospholipid (PL) (circles) cumulative signal magnitude, (b) relative abundance of known (triangles) and novel (diamonds) monoisotopic PL (c) the number of known (triangles) and novel (diamonds) monoisotopic PL peaks and (b) the contribution of number of known (triangles) and novel (diamonds) PL to total number of detected lipids.

The depth-dependent cumulative FT-ICR MS signal for total lipids and PL follow that of Iatroscan TLC-FID technique, indicating that although FT-ICR MS method is not quantitative it does provide semiquantitative observation of bulk lipid content with depth. The cumulative signal of all lipids in negative ionization mode decreased by $89 \%$ between the epipelagic and the abyssopelagic zones, while the PL cumulative signal declined by $78 \%$ (Fig. 5a). 
Gašparović, B., Penezić, A., Lampitt, R.S., Sudasinghe, N., Schaub, T. 2018. Phospholipids as a component of the oceanic phosphorus cycle. Mar. Chem. 250, 70-80.

Pre-print version

303

304

305

306

307

308

309

310

311

312

313

314

We have identified 4,908 monoisotopic compounds (i.e., contribution from ${ }^{13} \mathrm{C}$-containing species and other heavy nuclides are omitted) for the negative ionization sample set. In total, elemental compositions were assigned for 1,862 phosporus-containing species (38\%) of which only $27 \%$ have elemental compositions that match the database of known lipids. These novel P-containing lipids include both compounds that are in continuous DBE and carbon-number series as known lipids (i.e. same headgroup with more/less double bonds and or more/less acyl carbons than has been previously observed) as well as compounds that do not have previously reported structures. The relative abundance of known and novel PL shows a 5.1- and 4.7-fold decrease, respectively, from epipelagic to bathypelagic depths (Fig. 5b). We observed no significant trend in the number of known and novel PL between the surface and deep Atlantic (Fig. 5c), with a significantly higher diversity of PL at 200 and $300 \mathrm{~m}$ depth. The average number of known and novel PL per depth is 95 and 251, respectively. The diversity of known and novel PL molecules is higher at abyssopelagic depths (9.9\% and $29.6 \%$ of all lipids, respectively) than in the epipelagic (4.8\% and $17.4 \%$ of all lipids, respectively).

Known PL include phosphatidylglycerol (PG), phosphatidylcholine (PC), phosphatidylethanolamine (PE), phosphatidic acid (PA), phosphatidyl serine (PS), and phosphatidylinositol (PI) that was occasionally detected at some depths (Fig. 6). Oxidized and monoacyl forms are assigned but their contribution to the total PL signal was mainly below $0.1 \%$ for all depths and is not discussed further. Isomeric PC and PE are differentiated as ions of different polarity (PC is observed as a positively-charged ion and PE as a negatively-charged ion).

The relative abundance of known PL decreased with depth (Fig. 6a,e,i,m,r, and w). Among those $\mathrm{PL}$, the relative abundance decreased in the order $\mathrm{PG}<\mathrm{PE}<\mathrm{PA}<\mathrm{PC}<\mathrm{PS}<\mathrm{PI}$ from the epipelagic to the abyssopelagic zone. Molecular diversity of these lipids is reflected in 82 PG, 39 PC, 22 PE, 92 PA, 28 PS and 10 PI compounds detected. The water column distributions of their molecular diversities, i.e. the number of detected PL are shown in Figs. 6 b,f,j,n,s,and x. There is an increased diversity of PG and PA with depth (on average 15 PG and 12 PA formulas in the epipelagic, and 27 PG and 17 PA formulas in the abyssopelagic). In contrast, molecular diversity of PC and PE decreased between the epipelagic (12 PC and 11 PE formulas) and abyssopelagic (5 PC and 4 PE formulas). Their contribution to all lipid molecules increased down to the deep Atlantic for PG and PA, from the average of 1.2\% and 1.0\% respectively, in the epipelagic layer, to the average of $3.4 \%$ and $2.1 \%$ respectively, in the abyssopelagic 
Gašparović, B., Penezić, A., Lampitt, R.S., Sudasinghe, N., Schaub, T. 2018. Phospholipids as a component of the oceanic phosphorus cycle. Mar. Chem. 250, 70-80.

Pre-print version

332 layer. The contribution of PC, PE, PS and PI to all lipid molecules slightly decreased to less than $1 \%$ in 333 the deep Atlantic

334 The acyl double bond equivalents (DBE, the number of molecular rings plus double bonds to 335 carbon in a molecule) and the acyl chain length facilitate insight into the structural characteristics of 336 identified PL. Average DBE (Fig. 6d,h,l,p,u and z) decreased from surface to the deep ocean for all 6 337 identified PL. Detected PE were saturated below $200 \mathrm{~m}$ depth. The highest unsaturation in the epipelagic 338 zone was observed for a few detected PI (average DBE=5.6), while the lowest unsaturation at the surface 339 was observed for PG (average $\mathrm{DBE}=1.9$ ). The average number of carbon atoms in acyl chain (Fig. $3406 \mathrm{~d}, \mathrm{~h}, \mathrm{l}, \mathrm{p}, \mathrm{u}$ and $\mathrm{z}$ ) across ocean depths varies for PG (between 15.9 and 17.0 C atoms), for PC (between 34114.2 and 16.4 C atoms), for PE (between 15.5 and 17.6 C atoms), for PA (between 14.5 and $17.5 \mathrm{C}$ atoms), 342 for PS (between 13.5 and 17.3 C atoms) and for PI (between 15.3 and 19.0 C atoms). This highlights an 343 elongation in the PG, PC and PE acyl carbon chain in the abyssopelagic zone. 
Gašparović, B., Penezić, A., Lampitt, R.S., Sudasinghe, N., Schaub, T. 2018. Phospholipids as a component of the oceanic phosphorus cycle. Mar. Chem. 250, 70-80.

Pre-print version
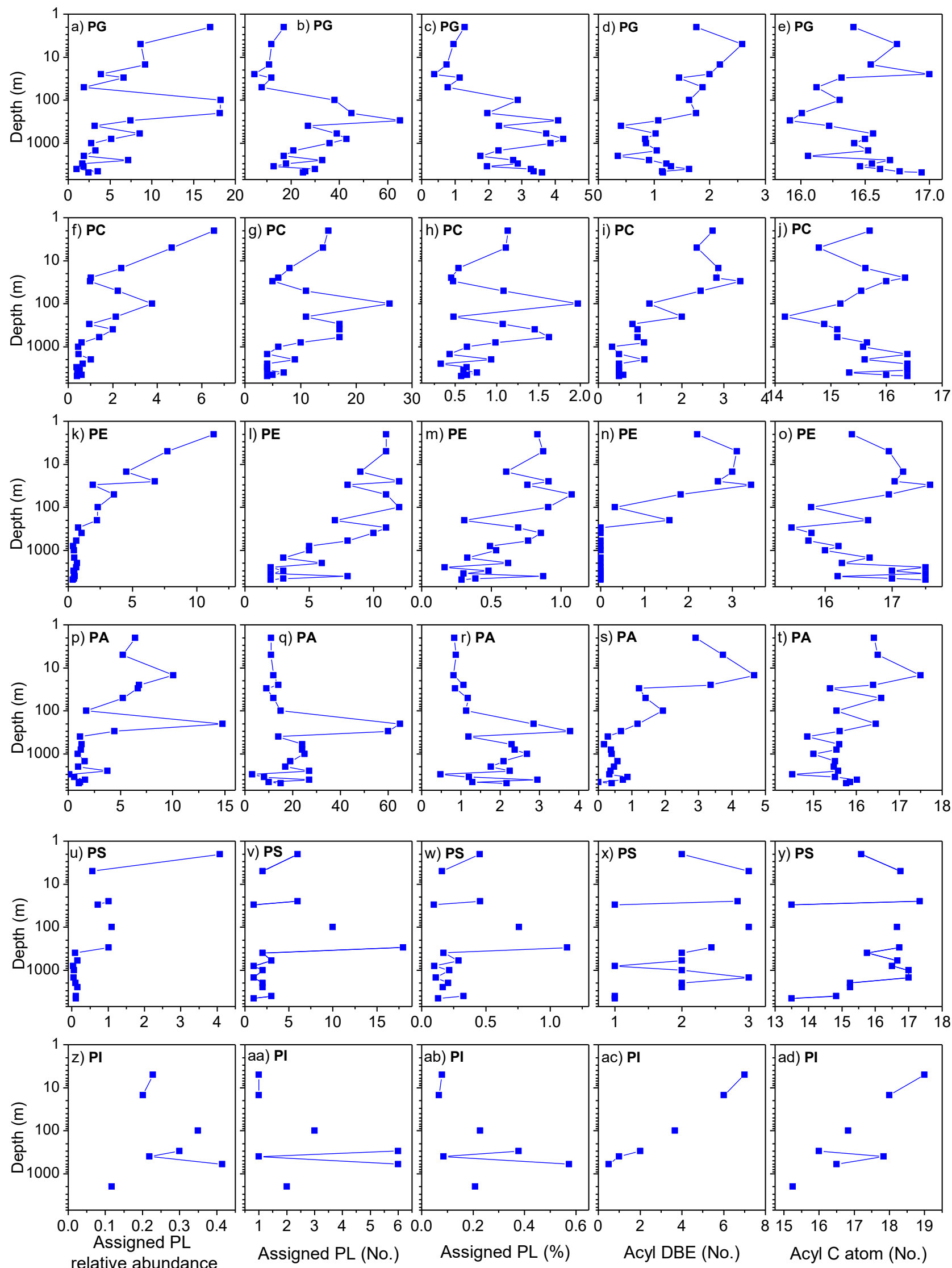
Gašparović, B., Penezić, A., Lampitt, R.S., Sudasinghe, N., Schaub, T. 2018. Phospholipids as a component of the oceanic phosphorus cycle. Mar. Chem. 250, 70-80.

Pre-print version

Fig. 6. Depth distribution of FT-ICR MS determined known phospholipids (PL): (a, f, k, p, u and z) PL relative abundance, (b, g, l, q, v and aa) the number of monoisotopic peaks, (c, h, m, r, w and ab) the contribution of PL molecular number to total number of detected lipids, (d, i, n, s, x, and ac) acyl double bond equivalents and (e, j, o, t, y and ad) acyl carbon number of (a-e) phosphatidylglycerol (PG), (f-j) phosphatidylcholine (PC), (k-o) phosphatidylethanolamine (PE), (p-t) phosphatidic acid (PA), (u-y) phosphatidyl serine (PS), and (z-ad) phosphatidylinositol (PI).

We have observed that some PL dominate in the epipelagic (0-100 $\mathrm{m}$ depth), or below the epipelagic to the abyssopelagic (100-4800 m depth). Table 1 shows acyl DBE (for known PL), molecular DBE (for novel PL) and carbon number of the most abundant (assuming similar ionization efficiency between PL) known lipids observed in the epipelagic and below the epipelagic and their contribution to the total known lipid class as well as to the total novel lipids.

Table 1. The elemental composition, average carbon number and double bond equivalents (DBE) of the acyl group, and their contribution to the lipid class, range and average value (in parentheses), for the most abundant lipids observed in the epipelagic (0-100 m) and below the epipelagic (100-4800 $\mathrm{m})$. The formula in bold represents the most abundant lipid compound observed in the whole water column.

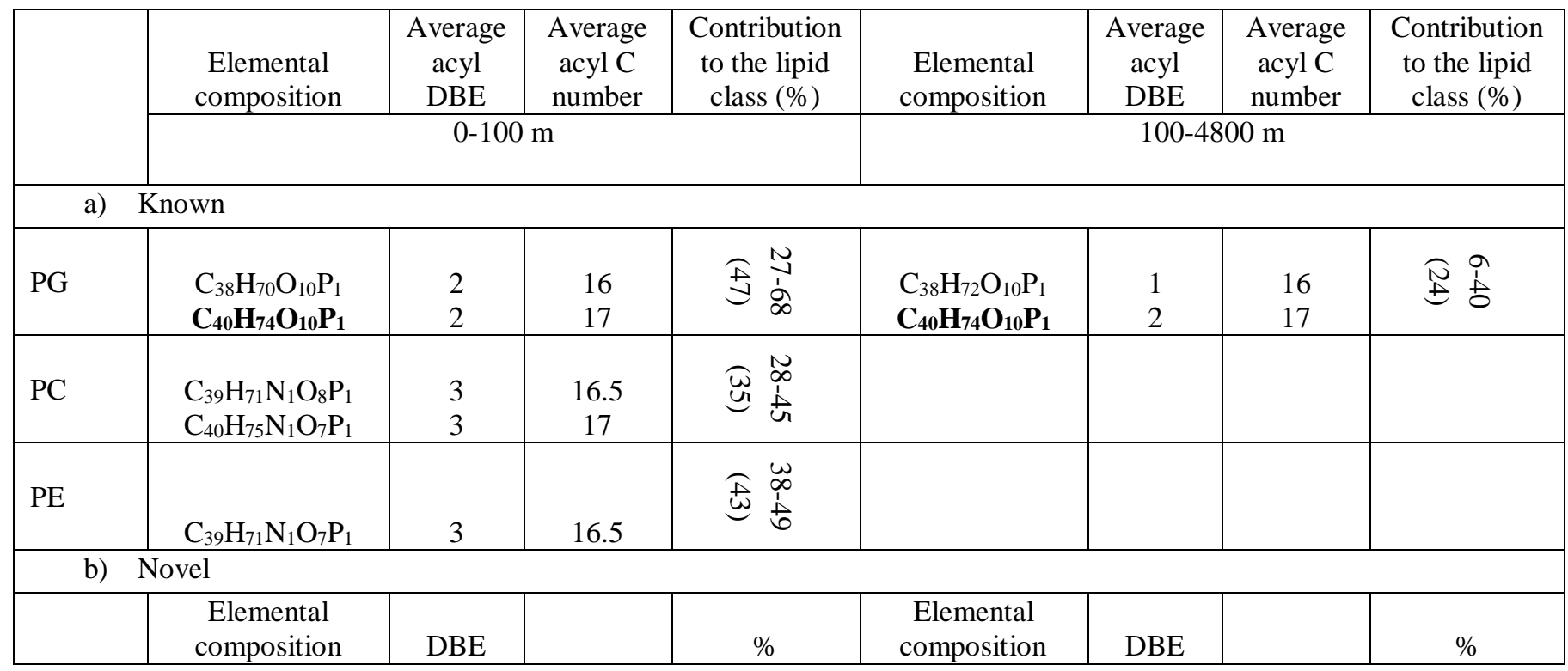


Gašparović, B., Penezić, A., Lampitt, R.S., Sudasinghe, N., Schaub, T. 2018. Phospholipids as a component of the oceanic phosphorus cycle. Mar. Chem. 250, 70-80.

Pre-print version

\begin{tabular}{|c|c|c|c|c|c|c|}
\hline $\mathrm{DBE}>0$ & $\begin{array}{l}\mathrm{C}_{39} \mathrm{H}_{71} \mathrm{~N}_{1} \mathrm{O}_{5} \mathrm{P}_{1} \\
\mathrm{C}_{36} \mathrm{H}_{67} \mathrm{~N}_{1} \mathrm{O}_{5} \mathrm{P}_{1} \\
\end{array}$ & $\begin{array}{l}5 \\
4\end{array}$ & $\theta \frac{i}{N}$ & $\mathrm{C}_{28} \mathrm{H}_{42} \mathrm{O}_{4} \mathrm{P}_{1}$ & 8 & $\infty_{0} \tilde{a}$ \\
\hline $\mathrm{DBE}=0$ & $\begin{array}{l}\mathrm{C}_{33} \mathrm{H}_{68} \mathrm{O}_{7} \mathrm{P}_{1} \\
\mathrm{C}_{31} \mathrm{H}_{64} \mathrm{O}_{7} \mathrm{P}_{1}\end{array}$ & $\begin{array}{l}0 \\
0\end{array}$ & (N) & $\begin{array}{l}\mathrm{C}_{20} \mathrm{H}_{42} \mathrm{O}_{6} \mathrm{P}_{1} \\
\mathrm{C}_{22} \mathrm{H}_{46} \mathrm{O}_{6} \mathrm{P}_{1}\end{array}$ & $\begin{array}{l}0 \\
0\end{array}$ & (둔 \\
\hline
\end{tabular}

364

365

366

367

368

369

To provide insight into the chemical characteristics of novel PL, we have categorized them into two groups; novel PL with at least one unsaturation (DBE $>0)$ and saturated (DBE=0) novel PL. The relative abundance of unsaturated novel PL decreased 5.0-fold, while for saturated PL relative abundance decreased 1.6-fold between the epipelagic and the abyssopelagic layers (Fig. 7a). The highest relative abundance decrease for unsaturated novel PL was observed between the epipelagic and the mesopelagic zones.

The number of novel saturated molecular formulae (Fig. 7b) increased from epipelagic (on average 18) to the abyssopelagic (average 45), with an increased contribution to total lipid diversity. Molecular diversity increased from an average $1.2 \%$ at the surface productive layer to $5.7 \%$ at the deepest Atlantic (Fig. 7c). The change in the number of unsaturated novel PL between the surface (on average 203 molecules) and deep ocean (average 192 molecules) is not significant, but a substantial increase was noticed in the mesopelagic layer (Fig. 7b). The contribution of novel unsaturated PL molecular formulas to total lipid molecular formulae increased between the epipelagic and the abyssopelagic zone from 16.2 to $23.8 \%$ (Fig. 7c). The molecular mass (Fig. 7d) of saturated and unsaturated novel PL increased with depth. For example, average molecular weight for saturated novel PL increased from $466.5 \mathrm{Da}$ (at the surface) to $648.7 \mathrm{Da}$ (at $4800 \mathrm{~m}$ ), whereas unsaturated PL showed an increase from $524.5 \mathrm{Da}$ (at the surface) to $623.1 \mathrm{Da}$ (at $4800 \mathrm{~m}$ ). Interestingly, we observe a depth-related increase in the degree of unsaturation of novel unsaturated PL from an average DBE value of 5.0 in the epipelagic to 6.7 in the abyssopelagic (Fig. 7e). 
Gašparović, B., Penezić, A., Lampitt, R.S., Sudasinghe, N., Schaub, T. 2018. Phospholipids as a component of the oceanic phosphorus cycle. Mar. Chem. 250, 70-80.

Pre-print version
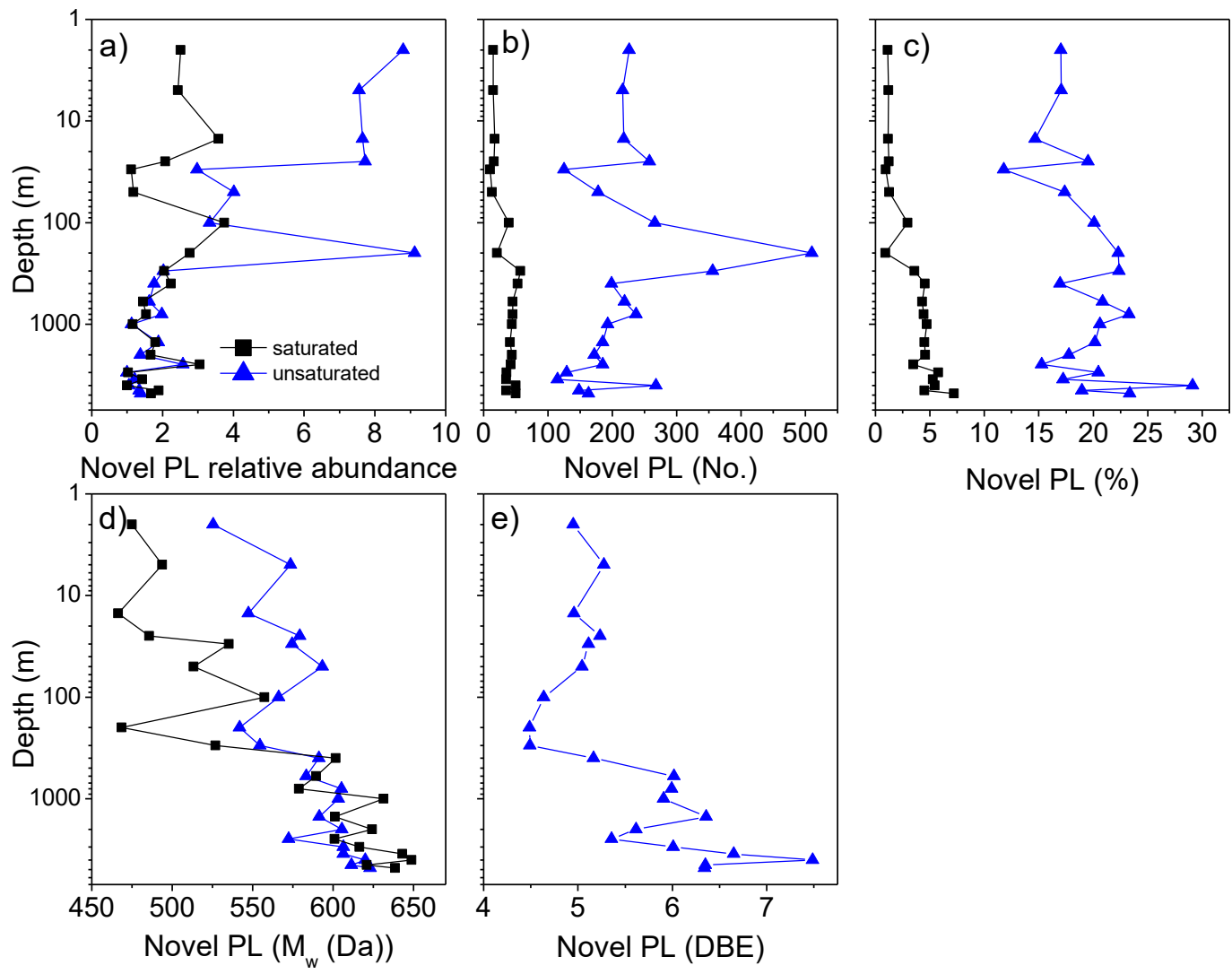

Novel PL (\%)

Fig. 7. Depth distribution of FT-ICR MS determined novel phospholipids: (a) relative abundance, (b) the number of monoisotopic peaks (No.), (c) the contribution of PL molecular formulas to total lipid molecular formulas (\%), (d) the average molecular weight and (e) double bond equivalents (DBE) for saturated (squares) and unsaturated (triangles) PL.

It is reasonable to assume that the majority of novel PL are products of depth related transformation of PL. Here we present depth-related average oxygen to carbon $(\mathrm{O} / \mathrm{C})$ and hydrogen to carbon $(\mathrm{H} / \mathrm{C}) \mathrm{ratio}$ variations of elaborated PL classes obtained in the negative ionization mode, with the intention to gain insight into the possible transformation mechanisms of PL in the whole water column. The average O/C ratio (Fig. 8a) varied more with depth than $\mathrm{H} / \mathrm{C}$ ratios (Fig. 8b). The highest $\mathrm{O} / \mathrm{C}$ was recorded for known PL (on average 0.24), and declined for saturated (on average 0.21) and unsaturated (on average 0.19) novel PL. PL characteristic is their richness in hydrogen and the $\mathrm{H} / \mathrm{C}$ ratios were on average $1.89,1.74$ and 2.09 for the known, novel unsaturated and novel saturated PL, respectively (Fig. 8b). 
Gašparović, B., Penezić, A., Lampitt, R.S., Sudasinghe, N., Schaub, T. 2018. Phospholipids as a component of the oceanic phosphorus cycle. Mar. Chem. 250, 70-80.

Pre-print version
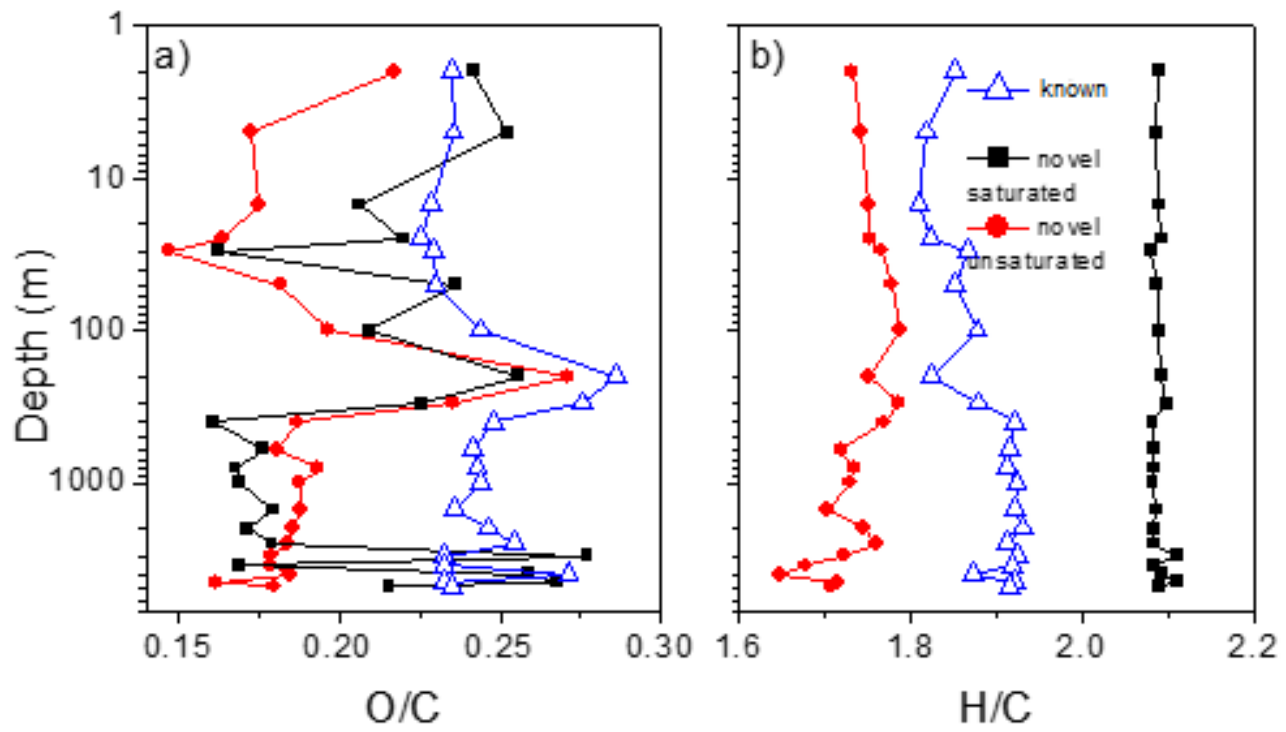

399

400 Fig. 8. Depth related FT-ICR MS data of (a) average oxygen to carbon (O/C) and (b) hydrogen to carbon 401 (H/C) ratios of known PL (triangles), novel unsaturated PL (circles) and novel saturated PL (squares). 
Gašparović, B., Penezić, A., Lampitt, R.S., Sudasinghe, N., Schaub, T. 2018. Phospholipids as a component of the oceanic phosphorus cycle. Mar. Chem. 250, 70-80.

Pre-print version

403

404

405

406

407

408

409

410

411

412

413

414

415

416

417

418

419

420

421

422

423

424

425

426

427

428

429

430

\section{Discussion}

Here, we have analyzed PL and identify them as known (database-matched) and novel. Known phospholipids, PG, PC, PE, PA, PS and PI, are discussed individually, while novel PL are analyzed and discussed as saturated $(\mathrm{DBE}=0)$ and unsaturated, having one or more double bonds $(\mathrm{DBE}>0)$. This approach provides a holistic assesment of PL in the Northeast Atlantic, in which the change in both relative abundance and composition occur most significantly in the upper regions of the water colum while PL are sinking to $4800 \mathrm{~m}$ depth in the Northeast Atlantic.

Lipids, like bulk POC, are produced primarily in surface waters by plankton and are largely recycled and degraded in sub-surface waters (Gašparović et al., 2014; Wakeham, 1995). Size-fractionated Chl $a$ measurements and pigment analysis revealed that the main lipid producers were nanophytoplankton prymnesiophytes and microphytoplankton diatoms. Although microphytoplankton contributed less to the total $\mathrm{Chl} a$ it seems that diatom bloom resulted in $\mathrm{SiO}_{4}{ }^{4-}$ depletion in the first $50 \mathrm{~m}$ of the water column. Judging from the $\mathrm{PO}_{4}{ }^{3-}$ concentrations it was not a limiting nutrient, knowing that $\mathrm{PO}_{4}{ }^{3-}$ threshold values for the phytoplankton uptake is $0.1 \mu \mathrm{mol} 1^{-1}$ (Justić et al., 1995).

The most significant output of phosphorus from the oceans is in organic debris sinking to the ocean floor and becoming incorporated into sedimentary rocks (Tyrell, 1999). The sinking particulate P pool (e.g., collected in sediment traps) is composed of particulate organic P (POP) ( 40\%), authigenic particulate inorganic $\mathrm{P}$ (PIP) ( 25\%), which is formed when organic $\mathrm{P}$ is remineralized and reprecipitated as calcium fluorapatite, and labile PIP (21\%), with lesser amounts of nonreactive detrital P ( 13\%) (Faul et al., 2005). In order to understand oceanic cycles of phosphorus and carbon, it is important to gain an insight into lipids that contribute to POP, as well as to POC, especially in the light of lipid selective accumulation in the ocean water column as POC sinks (Hwang and Druffel, 2003). As there are many unanswered questions regarding the global phosphorus cycle (Paytan and McLaughlin, 2007) we believe that our research will provide a means to better understand the $\mathrm{P}$ cycling in the ocean and the capability of PL for carbon sequestration.

Although total lipid and PL concentration, determined by the Iatroscan TLC/FID technique, decreased with depth, we observed that PL contribute to a significant fraction of POC (1.54\%) in the water 
Gašparović, B., Penezić, A., Lampitt, R.S., Sudasinghe, N., Schaub, T. 2018. Phospholipids as a component of the oceanic phosphorus cycle. Mar. Chem. 250, 70-80.

Pre-print version

431 column together with other lipid classes and a variety of other molecules that contribute to POC in the oceans. surface layer and recycling in deeper layers. We note that the contribution of PG and PA (Fig. 6c and o), together with novel saturated and unsaturated PL (Fig. 7.c) to all identified lipid molecules increased with depth, which indicated that those PL are selectively preserved among other lipid classes during particle sinking. Paytan et al. (2003) found that in a wide range of oceanic regimes a significant fraction of organic $\mathrm{P}$ (which includes PL) is exported to depths below the euphotic zone, although preferential regeneration of $\mathrm{P}$ relative to $\mathrm{C}$ occurs predominantly at shallow depths in the water column, but not deeper $(>300 \mathrm{~m})$ (Faul et al., 2005). There are several possible explanations for depth-related PL preservation. One means (Temelender et al., 2012). High pellet sedimentation rate should also contribute to $\mathrm{P}$ export from the epipelagic. Furthermore, Yoshimura et al. (2009) suggested that structural lipids (membrane compounds such as PL) remain stable during early lipid transformation due to the chemical interactions of the structural lipids with other organics. Depth-related enhanced contribution of PL molecules to all lipid molecules can also be explained by efficient particle export during diatom and coccolitophorides (Prymnesiophyceae) blooms. In general, diatom blooms can lead to substantial particle export that is transferred efficiently through the mesopelagic (Martin et al., 2011b). Coccolithophores, class Prymnesiophyceae, calcifying marine phytoplankton, are shown to bloom frequently and extensively in the North Atlantic (Brown and Yoder, 1994). They are considered to play an import role in the global carbon cycle through the production and export of organic carbon and calcite (O'Brien et al., 2013).

The major PL in many species of algae are PC, PE and PG. In addition, PS may also be found in substantial amounts. PI and PA are noted as minor compounds (Guschina and Harwood, 2009). PA is an essential phospholipid involved in membrane biosynthesis and signal transduction in all eukaryotes (Testerink and Munnik, 2011). In this work we assigned a variety of PG, PE, PC, PA, PS and PI molecules. Among them the most abundant with the highest molecular diversity were PG. Obviously PG were major plankton membrane forming lipids at PAP site. Although the relative abundance of all known PL decreases with depth, due to heterotrophic consumers that selectively degrade and alter PL, abiotic transformations, and a substantial decrease of life below the euphotic zone, they are preserved to a different degree across 
Gašparović, B., Penezić, A., Lampitt, R.S., Sudasinghe, N., Schaub, T. 2018. Phospholipids as a component of the oceanic phosphorus cycle. Mar. Chem. 250, 70-80.

Pre-print version

460

the water column. PG and PA are selectively preserved. We may eventually assume that those PL originated from fast settling particles coming from diatoms and prymnesiophytes. However, we are unable to explain the depth-related increased molecular variability of PG. It seems that a new source of PG contributed to PG diversity at $300 \mathrm{~m}$ depth. This could be due to the horizontal advection of water masses, transportation of old particles to the deep waters that were previously produced in the euphotic zone and/or newly produced prokaryotic biomass in-situ below euphotic zone.

We found PA as an important component of PL pool regarding high molecular diversity (Fig. 6.). We assume that PA can also be formed in-situ during the early transformation of PL. We propose two possible mechanisms that generate PA from other PL: nucleophilic substitution of the P atom enabled by abiotic hydrolysis or biotic enzymatic reaction with cleavage of glycerol, choline, ethanolamine, serine and inositol from PG, PC, PE, PS and PI, respectively.

Higher average unsaturation of known PL at the surface indicates their primary origin from plankton. Their depth related characteristics include loss of unsaturation. It is clear that saturated lipids are less prone to degradation and are therefore important organics for deep ocean carbon storage. It is not clear what would be the origin of PG, PC and PE acyl chain elongation in the abyssopelagic. One possible explanation would be that the majority of those lipids came from living cells and represent their acclimation to low temperature and high pressure, a feature that should be explored.

We have found that two PGs dominated in the surface productive layer (Table 1a). PG $\mathrm{C}_{38} \mathrm{H}_{70} \mathrm{O}_{10} \mathrm{P}_{1}$, with acyl DBE=2 and an average acyl carbon number of $16 \mathrm{C}$ per acyl chain, for which we assume that these acyl chains might be two 16:1(n-7) fatty acids, which is a marker for diatoms (Daalgstad et all., 2003). It is reasonable to assume that as we have found a strong signal of the diatom pigment Fucoxanthin in the epipelagic layer (Fig. 3). $\mathrm{PG} \mathrm{C}_{40} \mathrm{H}_{74} \mathrm{O}_{10} \mathrm{P}_{1}$, with $\mathrm{DBE}=2$ and an average acyl carbon number of $17 \mathrm{C}$ per acyl chain, was found to be dominant in the whole water column (Table 1a) indicating it as an important marker, probably of some living plankton origin. We anticipate two fatty acids 16:0 and 18:2(n-6), which are common for Prymnesiophyceae, for which the pigment 19HF was found to be the most abundant in our samples (Fig. 3). If it is so, then, we may conclude that a Prymnesiophyceae bloom was the cause of export of organic carbon and phosphorus. The average 16.5 carbons in the acyl chain of $\mathrm{PC} \mathrm{C}_{39} \mathrm{H}_{71} \mathrm{~N}_{1} \mathrm{O}_{8} \mathrm{P}_{1}$ and $\mathrm{PE} \mathrm{C}_{9}{ }_{9} \mathrm{H}_{71} \mathrm{~N}_{1} \mathrm{O}_{7} \mathrm{P}_{1}$ indicate that one of two fatty acids have an odd number of $\mathrm{C}$ atoms. An odd number of fatty acid C atoms point to PL of bacterial origin (Harkewicz and Dennis, 2011). 
Gašparović, B., Penezić, A., Lampitt, R.S., Sudasinghe, N., Schaub, T. 2018. Phospholipids as a component of the oceanic phosphorus cycle. Mar. Chem. 250, 70-80.

Pre-print version

We find a predominance of novel PL molecules in the North Atlantic samples that constituted an increasing molecular contribution to total lipid molecules detected. This implies their depth-related selective accumulation. Suzumura and Ingall (2004) found similar results while investigating different $P$ forms, including hydrophobic P (representing phospholipids) in the Pacific Ocean. They found that a fraction of the hydrophobic $\mathrm{P}$ is less reactive that withstands recycling in surface waters and is exported to deeper waters. In deep water preferential remineralization of non-hydrophobic compounds results in an increased abundance of hydrophobic $\mathrm{P}$ in both dissolved and particulate $\mathrm{OM}$ fractions relative to surface waters. They concluded that accumulation of less reactive hydrophobic P compounds in deep waters acts as a P sink from the marine ecosystems on a longer time scale.

Obviously, there is a lack of knowledge on the molecular form of phosphorus stored in lipids, production of those PL, and depth related molecular changes. Further research should be focused on those PL molecular identification to further elucidate oceanic P cycling. These PL are primarily non-aromatic in their molecular structure as illustrated from the Aromaticity Index (AI) (Koch and Dittmar, 2006) that is mainly $<0.5$ for the majority of novel lipids. We have found 1-4 molecular PL formulas per depth that satisfy the criteria for the existence of aromatic structures (AI > 0.5). For example, the two most often found PL formulas having AI>0.5 at a majority of depths are $\mathrm{C}_{28} \mathrm{H}_{24} \mathrm{O}_{2} \mathrm{P}_{1}(\mathrm{DBE}=17, \mathrm{AI}=0.56)$ and $\mathrm{C}_{29} \mathrm{H}_{22} \mathrm{~N}_{1} \mathrm{O}_{2} \mathrm{~S}_{1}(\mathrm{DBE}=19, \mathrm{AI}=0.60)$.

The degree of unsaturation of the novel unsaturated PL at the surface was quite high (average $\mathrm{DBE}=5$ ) and even higher than the majority of known PL with the exception of PI. We assume that the majority of those PL represent the first stage of PL degradation concluding from the fact that they are still isolated as a lipid fraction by the use of dichloromethane. However, we cannot ignore the possible contribution of in-situ biologically produced intact PL to novel PL, whose formulae and biological function so far are not know. A remarkable observation is an increase in the degree of unsaturation in the deep ocean (abyssopelagic average DBE=6.7). This degree of unsaturation is not easily explainable as PL transformation during particle sinking, because unsaturated organic compounds are generally considered as more reactive than saturated organics. One explanation would be that during PL transformation, crosslinking of unsaturated PL with other unsaturated organics or their fragments take place. This agrees with the findings of Yoshimura et al. (2009) that membrane compounds chemically interact with other organics. These processes would lead to the formation of molecules with higher unsaturation and consequently 
Gašparović, B., Penezić, A., Lampitt, R.S., Sudasinghe, N., Schaub, T. 2018. Phospholipids as a component of the oceanic phosphorus cycle. Mar. Chem. 250, 70-80.

Pre-print version

518

519

520

521

522

523

524

525

526

527

528

529

higher molecular sizes, as we observed (Fig. 7e). Another explanation would be that some proportion of those highly unsaturated PL might arise from deep ocean plankton, such as bacteria, and to a much lesser degree from protozooplankton, and mesozooplankton (Yamaguchi et al., 2002). De Carvalho and Caramujo (2012) have shown that deep ocean bacteria are able to produce polyunsaturated fatty acids helping the regulation of the membrane fluidity triggered by low temperature and high pressure and providing protection from oxidative stress. If there were plankton membrane PL among novel unsaturated lipids in the deep ocean they should contain elongated highly unsaturated fatty acids judging from the high increased molecular mass.

The relative abundance of novel saturated PL slightly decreased with depth, with an increased molecular contribution to the total lipid molecular number with depth. This suggest that during particle sinking PL chemical transformations lead to in-situ formation of new saturated PL compounds and this is in line with their depth related increased molecular diversity and molecular mass. Four dominant novel saturated PL (Table 1) are probably important PL transformation products.

We assume that most novel unsaturated and saturated PL are formed during the transformation of PL. Molecular transformation of lipids takes place by biotic (enzymatic peroxidation, biohydrogenated (Rontani and Koblížek, 2008)) and abiotic (photooxidation and autoxidation) degradation (Rontani, 2008). However, the chemical mechanisms of these processes are largely unknown at present. Photooxidation can be important within the euphotic layer, whereas autoxidation and biotransformation may occur throughout the water column (Rontani et al., 2009). Biotic (heterotrophic) degradation was important for sinking particles and increased with depth, whereas abiotic degradation dominated the suspended particle pool (Christodoulou et al. 2009). Harvey et al. (1995) have shown that oxygen has a substantial effect on the overall rates of decomposition of lipid and other major biochemical compounds. The fact that $\mathrm{O} / \mathrm{C}$ ratios of novel saturated and unsaturated PL are lower than O/C ratios of intact known PL implies that oxidative transformation of PL does not take a leading role in PL transformation. In fact, decreased oxygen content in all novel Pl indicates oxygen removal from the molecules. Judging from the decreased H/C ratio of novel unsaturated PL it seems that dehydrogenation is an important mechanism in their formation. Conversely, hydrogenation is important for the formation of novel saturated PL. Marine bacteria and fungi were shown to perform biohydrogenation (Rhead et al., 1971; Wakeham, 1989; Ferreira et al., 2015). 
Gašparović, B., Penezić, A., Lampitt, R.S., Sudasinghe, N., Schaub, T. 2018. Phospholipids as a component of the oceanic phosphorus cycle. Mar. Chem. 250, 70-80.

Pre-print version

\section{Conclusions}

Phosphorus cycling within the ocean is not well understood (Benitez-Nelson, 2000). Much remains to be determined regarding the distribution, composition, and spatial and temporal variability of particulate phosphorus. Chemical characterization of lipids in particulate organic matter (POM) is necessary not only for understanding the source but also for clarifying the mechanistic processes by which PL survive across ocean depths.

The application of high-resolution FT-ICR MS provided a detailed compositional overview of particulate PL in the Northeast Atlantic including elemental composition, saturation/unsaturation, molecular mass and $\mathrm{H} / \mathrm{C}$ and $\mathrm{O} / \mathrm{C}$ ratios that illustrates depth-related transformation mechanisms of PL. Apart from the known PL that derive from living plankton or fresh OM, we primarily observed saturated and unsaturated PL that have not been reported previously. We have shown that novel PL are selectively preserved among other lipid classes and are a vehicle for the transportation of phosphorus as well as for carbon to the deep ocean. Further focus should be applied to their in-depth molecular identification and resolving their possible ecological functions.

Major pathway of known PL (PG, PC, PE, PA, PS and PI) cycling includes depth related loss of unsaturation, with PA formed as the earliest transformation of PG, PC, PE, PS and PI. We assume that novel, more resistant to transformation, PL originate from known PL alteration, for which oxidative transformation is not an important transformation mechanism.

This work provide new light in the P cycling in lipids, molecular diversity as well as the depth related PL molecular changes.

Acknowledgements We thank crew of the RRS James Cook. We would like to thank Gayatri Dudeja and Zoe Morral for the pigment and POC sample collection and analysis. This work was funded by the grant from the Croatian Science Foundation under the project IP-11-2013-8607, by the United States National Science Foundation (IIA-1301346) and the Center for Animal Health and Food Safety at New Mexico State University. This work is a contribution of the European FP7 Projects EURO-BASIN and of the Natural Environment Research Council, UK, core programme. 
Gašparović, B., Penezić, A., Lampitt, R.S., Sudasinghe, N., Schaub, T. 2018. Phospholipids as a component of the oceanic phosphorus cycle. Mar. Chem. 250, 70-80.

Pre-print version

575 
Gašparović, B., Penezić, A., Lampitt, R.S., Sudasinghe, N., Schaub, T. 2018. Phospholipids as a component of the oceanic phosphorus cycle. Mar. Chem. 250, 70-80.

Pre-print version

\section{References}

Azam, F., 1998. Microbial control of oceanic carbon flux: the plot thickens. Science 280, 694-696.

Baturin, G.N., 2003. Phosphorus Cycle in the Ocean, Lithology and Mineral Resources, 38, 101-119.

Benitez-Nelson, C.R., 2000. The biogeochemical cycling of phosphorus in marine systems. Earth-Sci. Rev. 51, 109-135.

Blight, E.G., Dyer, W.J., 1959. A rapid method of total lipid extraction and purification. Can. J. Biochem. Physiol. 37, 911-917.

Brown, C., Yoder, J., 1994. Coccolithophorid blooms in the global ocean, J. Geophys. Res., 99, 74677482.

Buesseler, K.O., 1998. The decoupling of production and particulate export in the surface ocean. Global Biogeoch. Cycles 12, 297-310.

de Carvalho, C.C.C.R., Caramujo, M.J., 2012. Lipids of Prokaryotic Origin at the Base of Marine Food Webs. Mar. Drugs 10, 2698-2714.

Chelton, D.B., Schlax, M.G., Samelson, R.M., de Szoeke, R.A., 2007. Global observations of large oceanic eddies. Geophys. Res. Letters 0094-8276. 34 (15) p:L15606.

Christodoulou, S., Marty, J.C., Miquel, J.C., Volkman, J.K., Rontani, J.F., 2009. Use of lipids and their degradation products as biomarkers for carbon cycling in the northwestern Mediterranean Sea. Marine Chemistry 113, 25-40.

Dalsgaard, J., St John, M., Kattner, G., Müller-Navarra, D., Hagen, W., 2003. Fatty acid trophic markers in the pelagic marine environment. Adv. Mar. Biol. 46, 225-340.

Dobbs, F.C., Findlay, R.H., 1993. Analysis of microbial lipids to determine biomass and detect the response of sedimentary microorganisms to disturbance. In: Kemp, P.F., Sherr, B.F., Sherr, E.B., Cole, J.J. (Eds.), Handbook of Methods in Aquatic Microbial Ecology. Lewis Publisher, Boca Raton, FL, pp. 347-358.

Dugdale, R.C., Goering, J.J. 1967. Uptake of new and regenerated forms of nitrogen in primary productivity. Limnol. Oceanogr. 12, 196-206. 
Gašparović, B., Penezić, A., Lampitt, R.S., Sudasinghe, N., Schaub, T. 2018. Phospholipids as a component of the oceanic phosphorus cycle. Mar. Chem. 250, 70-80.

Pre-print version

602

603

604

605

606

607

608

609

610

611

612

613

614

615

616

617

618

619

620

621

622

623

624

625

626

627

Faul, K.L., Paytan, A., Delaney, M.L. 2005. Phosphorus distribution in sinking oceanic particulate matter. Mar. Chem., 97, 307-333.

Ferreira, I.M., Meira, E.B., Rosset, I.G., Porto, A.L.M., 2015. Chemoselective biohydrogenation of $\alpha, \beta-$ and $\alpha, \beta, \gamma, \delta$-unsaturated ketones by the marine-derived fungus Penicillium citrinum CBMAI 1186 in a biphasic system. J. Mol. Cat. B Enzym. 115, 59-65.

Frka, S., Gašparović, B., Marić, D., Godrijan, J., Djakovac, T., Vojvodić, V., Dautović, J., Kozarac, Z. 2011. Phytoplankton Driven Distribution Of Dissolved And Particulate Lipids In A Semi-Enclosed Temperate Sea (Mediterranean): Spring To Summer Situation. Estuar. Coast. Shelf Sci. 93, 290-304.

Gašparović, B., Frka, S., Koch, B.P., Zhu, Z.Y., Bracher, A., Lechtenfeld, O. J., Neogi, S.B., Lara, R.J., Kattner, G., 2014. Factors influencing particulate lipid production in the East Atlantic Ocean. Deep-Sea Res. Pt. I 89, 56-67.

Gašparović, B., Kazazić, S.P., Cvitešić, A., Penezić, A., Frka, S. 2015. Improved separation and analysis of glycolipids by Iatroscan thin-layer chromatography-flame ionization detection. J. Chromtogr. A $1409,259-267$.

Gašparović, B., Kazazić, S.P., Cvitešić, A., Penezić, A., Frka, S., 2017. Corrigendum to "Improved separation and analysis of glycolipids by Iatroscan thin-layer chromatography-flame ionization detection" [J. Chromatogr. A 1409 (2015) 259-267]. J. Chromtogr. A 1521, 168-169.

Geider, R.J., La Roche, J., 2002. Redfield revisited: variability of C:N:P in marine microalgae and its biochemical basis. Eur. J. Phycol. 37, 1-17.

Guschina I.A., Harwood J.L., 2009. Algal Lipids and Effect of the Environment on their Biochemistry. In: Arts, M.T., Brett, M.T., Kainz, M.J. (Eds.) Lipids in Aquatic Ecosystems. Springer, pp 1-24.

Harkewicz, R.; Dennis, E.A. Applications of mass spectrometry to lipids and membranes. Annu. Rev. Biochem. 2011, 80, 301-325.

Hartman, S.E., Larkin, K.E., Lampitt, R.S., Lankhorst, M., Hydes, D.J., 2010. Seasonal and inter-annual biogeochemical variations in the Porcupine Abyssal Plain 2003-2005 associated with winter mixing and surface circulation. Deep-Sea Res. II 57 (15), 1303-1312. 
Gašparović, B., Penezić, A., Lampitt, R.S., Sudasinghe, N., Schaub, T. 2018. Phospholipids as a component of the oceanic phosphorus cycle. Mar. Chem. 250, 70-80.

Pre-print version

628

629

630

631

632

633

634

635

636

637

638

639

640

641

642

643

644

645

646

647

648

649

650

651

652

653

654

Hartman, S.E., Lampitt, R.S., Larkin, K.E., Pagnani, M., Campbell, J., et al., 2012. The Porcupine Abyssal Plain fixed-point sustained observatory (PAP-SO): variations and trends from the Northeast Atlantic fixed-point time-series. ICES J. Mar. Sci. 69, 776-783.

Harvey, H.R., Tuttle, J.H., Bell, J., 1995. Kinetics of phytoplankton decay during simulated sedimentation, Changes in biochemical composition and microbial activity under oxic and anoxic conditions. Geochim. Cosmochim. Acta, 59, 367-3377.

Holguin, F.O., Schaub, T., 2013. Characterization of microalgal lipid feedstock by direct-infusion FTICR mass spectrometry. Algal Res. 2, 43-50.

Hwang, J., Druffel, E.R.M., 2003. Lipid-like material as the source of the uncharacterized organic carbon in the ocean? Science 299, 881-884.

Ivančić, I., Godrijan, J., Pfannkuchen, M., Marić, D., Gašparović, B., et al., 2012. Survival mechanisms of phytoplankton in conditions of stratification induced deprivation of orthophosphate: Northern Adriatic case study. Limnol. Oceanogr. 57, 1721-1731.

Karl, D.M., 2014. Microbially mediated transformations of phosphorus in the sea: new views of an old cycle. Ann. Rev. Mar. Sci. 6, 279-337.

Kirkwood, D. S. 1996. Nutrients: practical notes on their determination in seawater. ICES, Copenhagen, pp 1-25.

Koch, B.P., Dittmar, T., 2006. From mass to structure: an aromaticity index for high-resolution mass data of natural organic matter. Rapid Comm. Mass Spectrom. 20, 926-932.

Lampitt, R.S., Bett, B.J., Kiriakoulis, K., Popova, E.E., Ragueneau, O., Vangriesheim, A., Wolff, G.A., 2001. Material supply to the abyssal seafloor in the Northeast Atlantic. Prog. Oceanogr. 50, $27-$ 63.

Lampitt, R.S., Achterberg, E.P., Anderson, T.R., Hughes, J.A., Iglesias-Rodriguez, M.D., et al., 2008. Ocean fertilization: a potential means of geoengineering? Phil. Trans. Roy. Soc. A 366, 39193945.

Lee C., Wakeham, S., Arnosti C., 2004. Particulate organic matter in the sea: the composition conundrum. Ambio, 33, 565-575. 
Gašparović, B., Penezić, A., Lampitt, R.S., Sudasinghe, N., Schaub, T. 2018. Phospholipids as a component of the oceanic phosphorus cycle. Mar. Chem. 250, 70-80.

Pre-print version

655

656

657

658

659

660

661

662

663

664

665

666

667

668

669

670

671

672

673

674

675

676

677

678

679

Loh, A.N., Bauer, J.E. 2000. Distribution, partitioning and fluxes of dissolved and particulate organic C, $\mathrm{N}$ and $\mathrm{P}$ in the eastern North Pacific and Southern Oceans. Deep-Sea Res., I 47, 2287-2316.

Longhurst, A., 2007. Ecological Geography of the Sea, 2nd Ed. Academic Press, Amsterdam, p. 157-163.

Marić, D., Frka, S., Godrijan, J., Tomažić, I., Penezić, A., Djakovac, T., Vojvodić, V., Precali, R., Gašparović, B. 2013. Organic matter production during late summer-winter period in a temperate sea. Cont. Shelf Res. 55, 52-65.

Martin, P., Van Mooy, B.A.S., Heithoff, A., Dyhrman, S.T., 2011a. Phosphorus supply drives rapid turnover of membrane phospholipids in the diatom Thalassiosira pseudonana. The ISME J. 5, 10571060 .

Mayor, D.J., Sharples, C.J., Webster, L., et al. 2013. Tissue and size-related changes in the fatty acid and stable isotope signatures of the deep sea grenadier fish Coryphaenoides armatus from the CharlieGibbs Fracture Zone region of the Mid-Atlantic Ridge. Deep Sea Res. II 98, 421-430.

Martin, P., Lampitt, R.S., Perry, M.J., Sanders, R., Lee, C., D’Asaro, E., 2011b. Export and mesopelagic particle flux during a North Atlantic spring diatom bloom. Deep-Sea Res. I 58, 338-349.

Moore, C. M.; Mills, M. M.; Arrigo, K. R.; et al. 2013. Processes and patterns of oceanic nutrient limitation. Nat. Geosci. 6, 701-710.

O’Brien, C. J., Peloquin, J.A., Vogt, M., Heinle, M., Gruber, N., et al., 2013. Global marine plankton functional type biomass distributions: coccolithophores. Earth Syst. Sci. Data, 5, 259-276.

Parrish, C.C. 1987. Separation of aquatic lipid classes by Chromarod thin-layer chromatographywith measurement by Iatroscan flame ionization detection. Can. J. Fish. Aquat. Sci. 44, 722-731.

Paytan, A., McLaughlin, K., 2007. The Oceanic Phosphorus Cycle. Chem. Rev. 107, 563-576.

Paytan, A.; Cade-Menun, B. J.; McLaughlin, K.; Faul, K. L. Selective phosphorus regeneration of sinking marine particles: evidence from 31P-NMR. Mar. Chem. 2003, 82, 55-70.

Pond, D.W., Tarling, G.A., Mayor, D.J. 2014. Hydrostatic pressure and temperature effects on the membranes of a seasonally migrating marine copepod. Plos One 9, e111043. 
Gašparović, B., Penezić, A., Lampitt, R.S., Sudasinghe, N., Schaub, T. 2018. Phospholipids as a component of the oceanic phosphorus cycle. Mar. Chem. 250, 70-80.

Pre-print version

680

681

Popendorf, K.J., Tanaka, T., Pujo-Pay, M., Lagaria, A., Courties, C., Conan, P. Oriol, L., Sofen, L.E., Moutin, T., Van Mooy, B.A.S., 2011. Gradients in intact polar diacylglycerolipids across the Mediterranean Sea are related to phosphate availability. Biogeosciences, 8, 3733-3745.

Rhead, M.M., Eglinton, G., Draffan, G.H., England, P.J., 1971. Conversion of oleic acid to saturated fatty acids in Severn Estuary sediments. Nature 232, 327-330.

Rontani, J.-F., 2008. Photooxidative and autoxidative degradation of lipid components during the senescence of phototrophic organisms. In: Matsumoto, T. (Ed.), Phytochemistry Research Progress. Nova Science Publishers, pp. 115-144.

Rontani, J.-F., Koblížek, M., 2008. Regiospecific Enzymatic Oxygenation of cis-Vaccenic Acid in the Marine Phototrophic Bacterium Erythrobacter sp strain MG3. Lipids 43, 1065-1074.

Rontani, J.-F., Zabeti, N., Wakeham, S.G., 2009. The fate of marine lipids: Biotic vs. abiotic degradation of particulate sterols and alkenones in the Northwestern Mediterranean Sea. Mar. Chem. 113, 918.

Rontani, J-F, Charriere, B., Forest, A., Heussner, S., Vaultier, F., et al. 2012. Intense photooxidative degradation of planktonic and bacterial lipids in sinking particles collected with sediment traps across the Canadian Beaufort Shelf (Arctic Ocean). Biogeosciences, 9, 4787-4802.

Sebastián, M., Smith, A.F., González, J.M., Fredricks, H.F., Van Mooy, B., et al., 2016. Lipid remodelling is a widespread strategy in marine heterotrophic bacteria upon phosphorus deficiency, ISME J. 10, 968-978.

Suzumura, M., 2005. Phospholipids in marine environments: a review. Talanta 66, $422-434$.

Suzumura, M., Ingall, E.D. 2004. Distribution and dynamics of various forms of phosphorus in seawater: insights from field observations in the Pacific Ocean and a laboratory experiment. Deep-Sea Res. I 51, 1113-1130.

Slocombe, S.P., Ross, M., Thomas, N., McNeill, S., Stanley, M.S., 2013. A rapid and general method for measurement of protein in micro-algal biomass. Bioresource Technol. 129, 51-57. 
Gašparović, B., Penezić, A., Lampitt, R.S., Sudasinghe, N., Schaub, T. 2018. Phospholipids as a component of the oceanic phosphorus cycle. Mar. Chem. 250, 70-80.

Pre-print version

705

706

707

708

709

710

711

712

713

714

715

716

Tamelander, T., Aubert, A.B. Wexels Riser, C., 2012. Export stoichiometry and contribution of copepod faecal pellets to vertical flux of particulate organic carbon, nitrogen and phosphorus. Mar. Ecol. Prog. Ser. 459, 17-28.

Testerink, C., Munnik, T., 2011. Molecular, cellular, and physiological responses to phosphatidic acid formation in plants. J. Exp. Bot. 62, 2349-2361.

Tyrrell, T., 1999. The relative influences of nitrogen and phosphorus on oceanic primary production. Nature, 400, 525-531.

Van Mooy, B.A.S., Rocap, G., Fredricks, H.F., Evans, C.T., Devol, A.H., 2006. Sulfolipids dramatically decrease phosphorus demand by picocyanobacteria in oligotrophic marine environments, Proc. Natl. Acad. Sci., 103, 8607-8612.

Van Mooy, B.A.S., Fredricks, H.F., Pedler, B.E., Dyhrman, S.T., Karl, D.M., et al., 2009. Phytoplankton in the ocean use non-phosphorus lipids in response to phosphorus scarcity. Nature 458, 69-72.

Van Mooy, B.A.S., Fredricks, H.F., 2010. Bacterial and eukaryotic intact polar lipids in the eastern subtropical South Pacific: Water-column distribution, planktonic sources, and fatty acid composition. Geochim. Cosmochim. Acta 74, 6499-6516.

Wakeham, S.G., 1989. Reduction of stenols to stanols in particulate matter at oxic-anoxic boundaries in sea water. Nature $342,787-790$.

Wakeham, S.G., 1995. Lipid biomarkers for heterotrophic alteration of suspended particulate organic matter in oxygenated and anoxic water columns of the ocean. Deep Sea Res. I 10, 1749-1771.

Wakeham, S.G., Hedges, J.I., Lee, C., Peterson, M. L., Hernes, P.J., 1997. Compositions and transport of lipid biomarkers through the water column and surficial sediments of the equatorial Pacific Ocean, Deep-Sea Res. II, 44, 2131-2162.

Wallmann, K., 2010. Phosphorus imbalance in the global ocean? Global Biogeochem. Cycles 24, B4030.

Weaver, P.P.E., Wynn, R.B., Kenyon, N.H., Evans, J.M., 2000. Continental margin sedimentation, with special reference to the north-east Atlantic margin. Sedimentology 47, 239-256.

Welschmeyer, N.A., 1994. Fuorometric analysis of chlorophyll a in the presence of chlorophyll b and pheopigments. Limnol. Oceanogr. 39, 1985-1992. 
Gašparović, B., Penezić, A., Lampitt, R.S., Sudasinghe, N., Schaub, T. 2018. Phospholipids as a component of the oceanic phosphorus cycle. Mar. Chem. 250, 70-80.

Pre-print version

732 Williams, R.G., Roussenov, V., Follows, M.J., 2006. Nutrient streams and their induction into the mixed layer. Global Biogeochem. Cycles 20, GB1016.

734 Wu, J.F., Sunda, W. Boyle, E.A., Karl D.M., 2000. Phosphate depletion in the western North Atlantic 735

736 Yamaguchi A., Watanabe, Y., Ishida, H., Harimoto, T., Furusawa, K., Suzuki, S., Ishizaka, J., Ikeda, T., 737 Mac Takahashi M., 2002. Structure and size distribution of plankton communities down to the 738 739 740 greater depths in the western North Pacific Ocean. Deep-Sea Res. II 49, 5513-5529.

Yamaguchi, A., Watanabe, Y., Ishida, H., Harimoto, T., Maeda, M., Ishizaka, J., Ikeda, T., Takahashi, M.M., 2005. Biomass and chemical composition of net-plankton down to greater depths (0-5800 m) in the western North Pacific Ocean. Deep-Sea Res. I 52, 341-353.

742 Yoshimura, T., Nishioka, J., Saito, H., Takeda, S., Tsuda, A., Wells, M.L., 2007. Distributions of 743 particulate and dissolved organic and inorganic phosphorus in North Pacific surface waters. Mar. Chem. 103, 112-121. 